\title{
Sequential actions of $B M P$ receptors control neural precursor cell production and fate
}

\author{
David M. Panchision, ${ }^{1}$ James M. Pickel, ${ }^{1}$ Lorenz Studer, ${ }^{1,2}$ Sang-Hun Lee, ${ }^{1,3}$ Patricia A. Turner, ${ }^{1,4}$ \\ Thomas G. Hazel, ${ }^{1,5}$ and Ronald D.G. McKay ${ }^{1,6}$ \\ ${ }^{1}$ Laboratory of Molecular Biology, NINDS, National Institutes of Health, Bethesda, Maryland 20892-4092, USA; ${ }^{2}$ Laboratory \\ of Stem Cell and Tumor Biology, Neurosurgery and Cellular Biochemistry and Biophysics, Memorial Sloan Kettering Cancer \\ Center; New York, New York 10021, USA
}

Bone morphogenetic proteins (BMPs) have diverse and sometimes paradoxical effects during embryonic development. To determine the mechanisms underlying BMP actions, we analyzed the expression and function of two BMP receptors, BMPR-IA and BMPR-IB, in neural precursor cells in vitro and in vivo. Neural precursor cells always express Bmpr-1a, but Bmpr-1b is not expressed until embryonic day 9 and is restricted to the dorsal neural tube surrounding the source of BMP ligands. BMPR-IA activation induces (and Sonic hedgehog prevents) expression of Bmpr-1b along with dorsal identity genes in precursor cells and promotes their proliferation. When BMPR-IB is activated, it limits precursor cell numbers by causing mitotic arrest. This results in apoptosis in early gestation embryos and terminal differentiation in mid-gestation embryos. Thus, BMP actions are first inducing (through BMPR-IA) and then terminating (through BMPR-IB), based on the accumulation of BMPR-IB relative to BMPR-IA. We describe a feed-forward mechanism to explain how the sequential actions of these receptors control the production and fate of dorsal precursor cells from neural stem cells.

[Key Words: Bone morphogenetic protein; receptor; neural; development; precursor cell]

Received March 9, 2001; revised version accepted June 19, 2001.

Animal development involves a complex progression of tissue induction and morphogenesis, expansion of precursor cell populations, and the death or terminal differentiation of these cells into specific functional types. Bone morphogenetic protein (BMP) signaling is repeatedly used in this dynamic process for both vertebrates and invertebrates. In gastrulating Xenopus and Drosophila, BMPs and the BMP2/4 homolog Decapentaplegic $(D p p)$ contribute to specifying the embryonic dorsoventral axis. High activity of $\mathrm{BMP} / \mathrm{Dpp}$ induces blood/ amnioserosa, whereas maximal inhibition of $\mathrm{BMP} / D p p$ leads to neural ectoderm induction (Dale 2000; Nakayama et al. 2000). Subsequently, BMP/Dpp signaling contributes to the specification and/or expansion of many tissues such as vertebrate limb and Drosophila wing (Vogt and Duboule 1999; Day and Lawrence 2000) and neural ectoderm (Cornell and Ohlen 2000).

Vertebrate neural ectoderm undergoes a period of rapid

Present addresses: ${ }^{3}$ Department of Biochemistry, College of Medicine, Hanyang University, Haengdang-dong, Sungdong-ku, 133-791, Seoul, South Korea; ${ }^{4}$ University of Maryland Biotechnology Institute, University of Maryland-Baltimore County, Baltimore, MD 21201, USA; ${ }^{5} \mathrm{Neu}$ ralStem Biopharmaceuticals, Bethesda, MD 20817, USA.

${ }^{6}$ Corresponding author.

E-MAIL mckay@codon.nih.gov; FAX (301) 402-1340.

Article and publication are at http://www.genesdev.org/cgi/doi/10.1101/ gad.894701. proliferation and morphogenetic movements to form a neural tube, as signals from adjacent tissues induce dorsal-ventral and anterior-posterior identities on precursors (Altmann and Brivanlou 2001). BMPs are expressed at high levels in nonneural ectoderm and then in the roof plate of the neural tube (Liem et al. 1995; Furuta et al. 1997). A BMP activity gradient induces dorsal identity markers indicative of neural crest or dorsal interneuron precursors (Liem et al. 1997; Nguyen et al. 1998, 2000; Barth et al. 1999|. However, BMPs also cause apoptosis in early central nervous system (CNS) precursor cells (Graham et al. 1996; Furuta et al. 1997), neuronal differentiation in mid-gestation CNS precursors (Li et al. 1998; Mehler et al. 2000), and glial differentiation in late embryonic or adult CNS precursors (Gross et al. 1996).

It is unclear how BMPs mediate such a wide variety of responses, but it may be a result of diversity in the components of signal transduction. Some BMP-related ligands are known to be involved in the generation of specific cell types (Shah et al. 1996; Lee et al. 1998), but there is evidence that many act in a redundant manner (Dudley and Robertson 1997; Solloway et al. 1998; Zhao et al. 1999). BMPs exert their effects by activating a complex of type I and type II receptors. The type II receptor is the primary ligand-binding component; both BMPRII and ActRIIB are functional type II receptors for BMPs. 
Type I receptors also have BMP-binding properties but are primarily responsible for transducing the signal into the cell: BMPR-IA (Alk3), BMPR-IB (Alk6), and ActR-I (Alk2) are all known to transduce BMP signals (Kawabata et al. 1998). The activated type I receptors in turn phosphorylate the DNA-binding proteins Smad1, Smad5, and Smad8, each of which can then heteromerize with Smad4 and translocate to the nucleus to regulate transcription of downstream target genes (Itoh et al. 2000).

The expression patterns of Bmpr-1a and Bmpr-1b in the CNS (Dewulf et al. 1995; Zhang et al. 1998) suggest that they have distinct roles in the transduction of BMP signals. In an effort to understand their role in neural development, we used multipotent CNS stem cells as a defined system to understand signals that control proliferation and fate choice (Johe et al. 1996; Studer et al. 1998). We have also developed a vector using POU-regulated genomic elements that control expression of the intermediate filament gene nestin in CNS precursor cells (Josephson et al. 1998). This vector, called pNERV, expresses mutant BMP receptors selectively in CNS stem cells in vitro and in transgenic mice. Using these tools, we show that most of the known actions of BMPs during neural precursor development can be attributed to the distinct actions of BMPR-IA and BMPR-IB. Furthermore, the activities of these receptors are linked sequentially, with BMPR-IA acting first and inducing the expression of Bmpr-1b. These results identify a feed-forward mechanism by which BMPs can control both the production and fate of precursor cells.

\section{Results}

Manipulating BMP receptor expression in neuroepithelial precursors

Extending on previous studies (Dewulf et al. 1995), we observed Bmpr-1a mRNA expression in all proliferative zones of the neural tube after gastrulation (Fig. 1A), regardless of location along the anterior-posterior or dorsal-ventral axis. In contrast, Bmpr-1b mRNA expression was not seen at embryonic day (E) 8.75 or earlier but was first detected at E9.0 (Fig. 1B). It was expressed along the entire anterior-posterior axis but was restricted to the dorsal domain of the neural tube. Expression of Bmpr-1b (and to a lesser extent Bmpr-1a) was lower in the extreme dorsal-most domains corresponding to the roof plate and choroid plexus epithelium. Expression of both receptors was greatly reduced in postmitotic mantle layers in forebrain, hindbrain, and spinal cord (Fig. 1A,B), indicating that they are down-regulated after terminal differentiation.

To further examine the role of BMP receptors in nervous system development, we generated constructs expressing constitutively active (ca) or dominant-negative (dn) forms of BMP receptors (Zou et al. 1997) under the control of a new nestin promoter-based vector called pNERV (Fig. 1C; see Materials and Methods). Expression of pNERV-driven constructs was strong in cultured CNS stem cells and was used for in vitro analysis of BMP receptor signaling. In vivo, transgene expression was exclusively localized to the proliferating neuroepithelium and neural crest (Fig. 1D,E). We observed very few position effects, possibly because the $5.4-\mathrm{kb}$ nestin basal promoter contains A/T rich sequences similar to previously described matrix attachment regions /Charron et al. 1995). In situ mRNA expression, epitope tag staining, and intensity of phenotype correlated well with transgene dose for each receptor at all ages analyzed (Fig. 1D,E). As expected, transgene expression under pNERV diminished once cells became postmitotic in older embryos. At all transgene doses, mice expressing caBmpr$1 a$ showed qualitatively different gross phenotypes from those expressing caBmpr-1b (Table 1; Fig. 1D,E), suggesting that each receptor mediated distinct responses.

\section{BMPR-IA activation increases precursor cell numbers}

Embryos expressing caBmpr-1a could be readily distinguished from wild-type or caBmpr-1b embryos by a failure of the tail to elongate properly. This stubby, curly "pig-tail" was apparent by E12.5 and, along with an occasional cranial hematoma, was generally the only external sign of abnormality in these embryos (Fig. 2A,B). These animals died between E17.5 and birth, as no transgenics were found in newborn litters. Dissection of embryos revealed a pronounced gyrus-like appearance to the hindbrain and spinal neuroepithelium by E11.5 (Fig. 2C$\mathrm{L})$, leading to a dense packing of cells by E12.5 that obscured the ventricular lumen. This phenotype was observed in almost all caBmpr-1a transgenic embryos before E13 (Table 1). Because tissue gyrification is an indicator of increased proliferation, bromodeoxyuridine (BrdU) incorporation was assayed in wild-type versus transgenic embryos at two ages. At E11.5, the number of $\mathrm{BrdU}^{+}$cells in the spinal cord of caBmpr-1a embryos was twofold higher $(P<0.01)$ than that of wild-type littermates (Fig. 2M). This proliferative effect was most pronounced in the dorsal neural tube. E14.0 caBmpr-1a embryos also showed twofold higher BrdU labeling than that of their wild-type littermates (Fig. $2 N_{;} P<0.01$ ), although the total number of proliferating cells was lower than that at E11.5. This suggested that BMPR-IA activation promotes proliferation in precursor cells throughout development.

\section{Early dorsal patterning is induced by BMPR-IA activation}

Inspection of the anterior neural tube revealed that the normal bilateral telencephalic vesicles (Fig. 3A,C) had been transformed in caBmpr-1a embryos into a single vesicle lacking a defined dorsal midline (Fig. 3B,D). This holoprosencephaly (Golden 1999) occurred with moderate and high transgene copy numbers (Table 1; Fig. 1D), was first seen at E11.5, and was severe at E15.5 (Fig. 3P). In the older animals, the entire alar domain rostral to the midbrain-hindbrain boundary was transformed into a cuboidal epithelium of single-cell thickness (Fig. 3N,P). 
Panchision et al.

Figure 1. Bmpr expression in wild-type and transgenic embryos. (A) In situ hybridization for Bmpr-1a on wild-type embryos showing normal expression pattern during development; note ubiquitous expression in proliferating ventricular zone and lack of expression in differentiated mantle layer. Dorsal-ventral axis of neural tube is indicated by arrows. $(B)$ In situ hybridization for $B m p r-1 b$ on wild-type embryos showing normal expression pattern during development; note that expression is restricted to dorsal proliferating neuroepithelium and is not expressed in postmitotic mantle layer. All images in $A$ and $B$ are from adjacent sections except for E15.5 sections. $(C)$ Diagram of construct (pNERV) used to control expression of mutant bone morphogenetic protein (BMP) receptors for all experiments. $(D, E)$ Examples of transgene expression at E10.5 (moderate copy number, c.n.), E11.5 (lower c.n.), and E13.5-E14.0 (high c.n.). In situ mRNA hybridization for Bmpr-1a $(D)$ or $B m p r-1 b \quad(E)$ shows ratio of receptor mRNA expression in wild-type versus transgenic embryos. Insets show Southern blot of pNERV transgene band just above endogenous nestin second intron band. Note distinct phenotypes caused by each transgene. Also note diminished transgene expression in older embryos. D, Dorsal; $\mathrm{V}$, ventral; $\mathrm{FB}$, forebrain; $\mathrm{MB}$, midbrain; $\mathrm{HB}$, hindbrain; SC, spinal cord; VZ, ventricular zone; and ML, mantle layer. $(A, B)$ Bar, 500 $\mu \mathrm{m}$ for E10.5 and $500 \mu \mathrm{m}$ for E12.5 and E15.5; $(D, E)$ bar, $200 \mu \mathrm{m}$ for E10.5 and E11.5 and $500 \mu \mathrm{m}$ for E13.5 and E14.0.

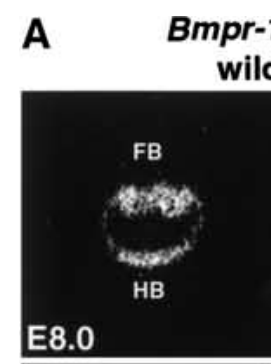

pr-1a mRNA
wild type
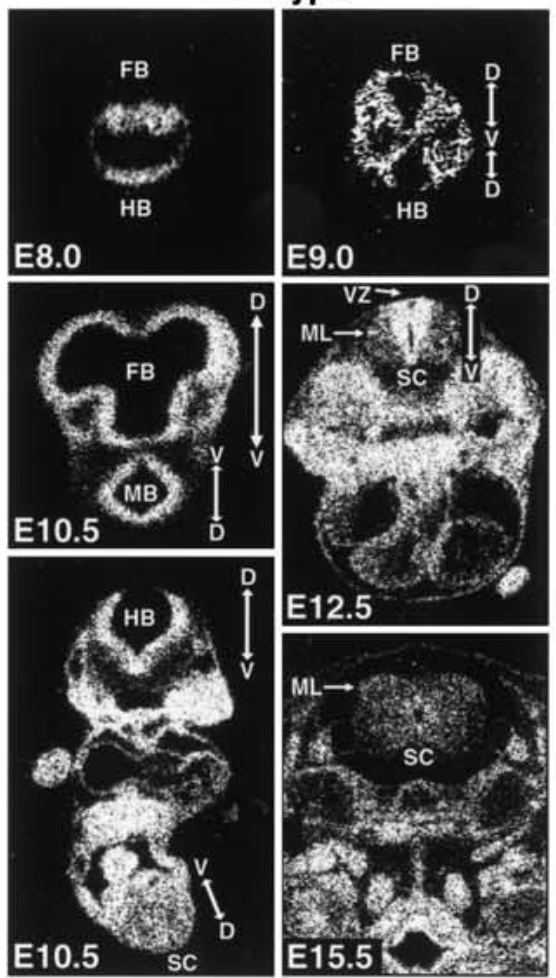

C

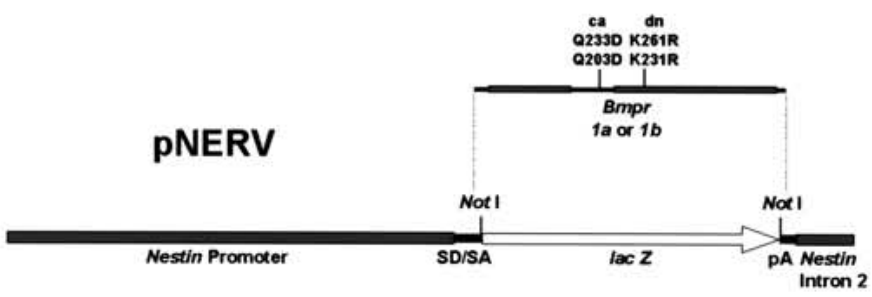

D

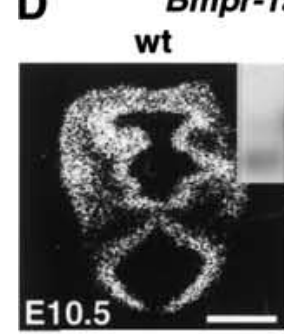

Bmpr-1a mRNA
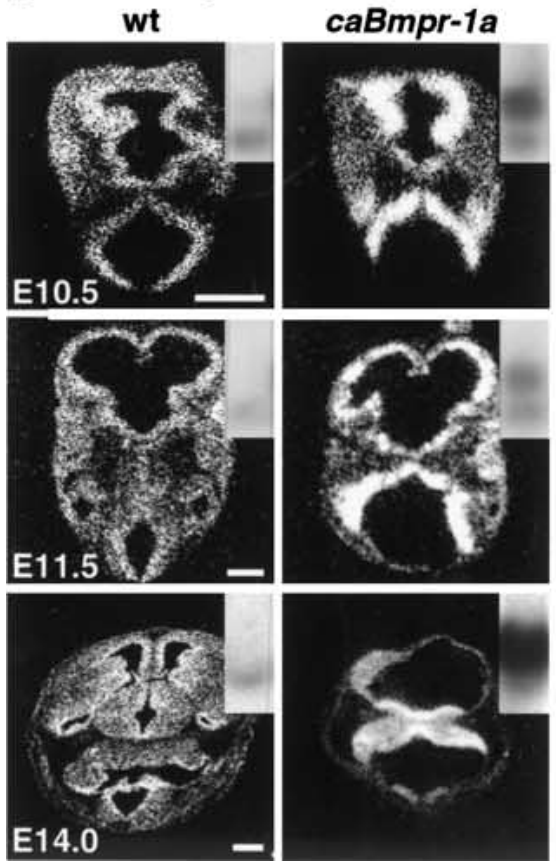

B

Bmpr-1b mRNA wild type
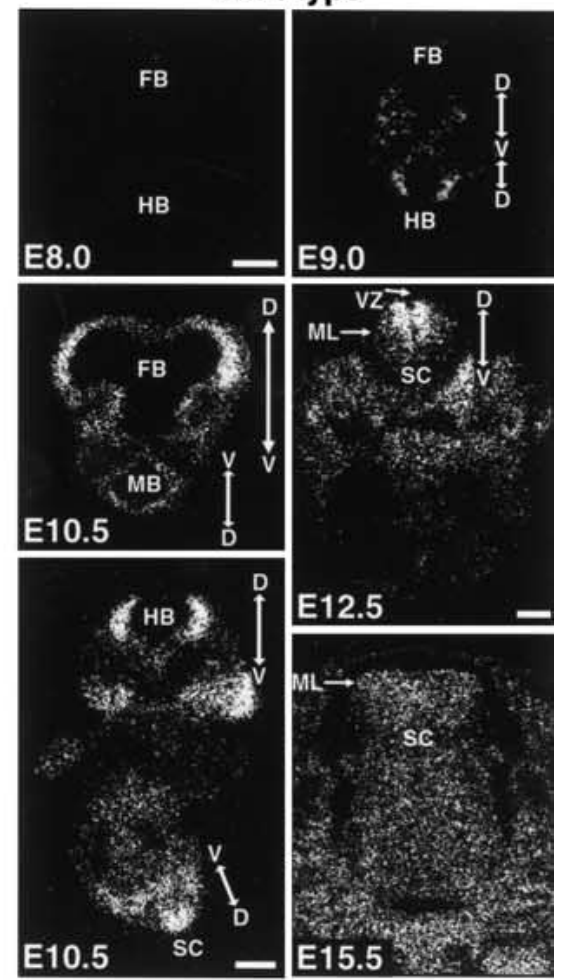

E Bmpr-1b mRNA

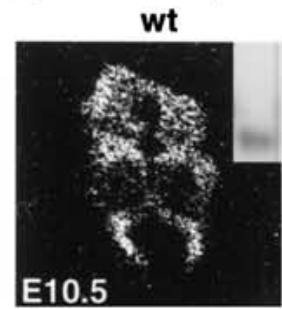
$c a B m p r-1 b$
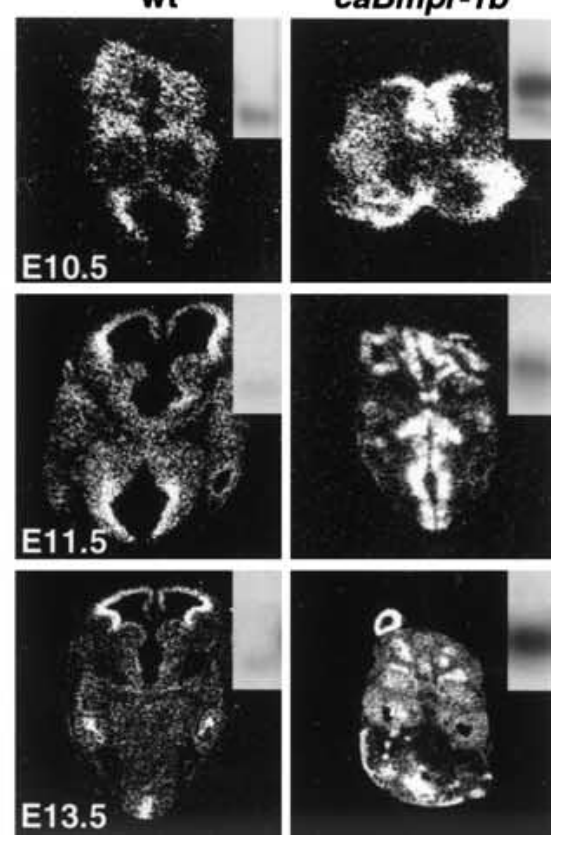
Table 1. Summary of gross phenotypes from caBmpr-1a and caBmpr-1b transgenics

\begin{tabular}{lccc}
\hline & & \multicolumn{2}{c}{ \# expressing/\# transgenic } \\
\cline { 3 - 4 } Phenotype & Age range & caBmpr-1a & caBmpr-1b \\
\hline Open fore/midbrain & E10.0-E15.5 & $2 / 19$ & $15 / 20$ \\
Complete exencephaly & E10.0-E15.5 & $1 / 19$ & $9 / 20$ \\
Collapsed neural tube & E10.0-E15.5 & $0 / 19$ & $15 / 20$ \\
Holoprosencephaly & E11.0-E15.5 & $7 / 17$ & $0 / 13$ \\
Gyrification & E11.0-E12.5 & $10 / 11$ & $2 / 10$ \\
Cell migation/mixing & E12.5-E15.5 & $5 / 7$ & $5 / 6$ \\
\hline
\end{tabular}

This cuboidal morphology most closely resembled choroid plexus, which is the most dorsal CNS cell type generated in the anterior neural tube. In situ analysis of the choroid plexus marker Foxj1 (formerly known as Hfh4; Fig. 3E,G; Lim et al. 1997; Kaestner et al. 2000) indicated that its expression had expanded to include the entire alar domain of the forebrain and midbrain (Fig. 3F,H). The basal plate remained Foxj1 negative. In contrast to the choroid plexus, the cortex and ganglionic eminence are derived from a less dorsal anlage in the neural tube and specifically express Foxg1 (formerly known as Bf1; Fig. 3I,K; Tao and Lai 1992; Kaestner et al. 2000). In caBmpr-1a embryos, Foxg1 expression (Fig. 3J,L,Q) was replaced by expression of Foxi1 (Fig. 3F,H,Q). As with Foxi1, the basal plate remained Foxg1 negative.

The hindbrain and spinal cord were also analyzed for induction of dorsal markers. The domain of Wnt1 expression, which is normally restricted to the roof plate and adjacent dorsal commissural precursors (Fig. 4A), was expanded to include the entire alar domain of the neural tube in caBmpr-1a embryos (Fig. 4B). Pax7, a dorsal precursor marker that in the mouse has a pattern of expression complementary to Wnt-1 (Fig. 4C), was diminished or extinguished from the dorsal neural tube (Fig. 4D). No ectopic Wnt1 and Pax7 expression was seen in the ventral neural tube (Fig. 4B,D), and ventral expression of Pax6 was unaffected in the caBmpr-1a animals (Fig. 4E,F). Thus, caBmpr-1a expression dorsalized the alar domain along the entire rostrocaudal axis of the neural tube, but its effects were not seen in the ventral-most neural tube (Figs. 3Q, 4G).

\section{Apoptosis is the early response to BMPR-IB activation}

In contrast to caBmpr-1a transgenics, embryos expressing caBmpr-1b had obvious gross abnormalities in the rostral neural tube (Fig. 5A-H). As early as E10.5, openings in the forebrain and midbrain neuroepithelium could be detected because of either failed closure of the neural tube or subsequent re-opening. Nearly all embryos age E11 or older showed exencephaly or at least partial neural tube opening, and almost all animals displayed a collapsed lumen in the caudal neural tube (Table 1; Fig. 6A,B). No transgenics were recovered among newborn litters, indicating that the mice died at or before birth.

As the phenotype of these embryos strongly suggested a dysregulation of cell death (Haydar et al. 1999), we measured the expression of the proteolytically activated form of Caspase 3 as an indicator of apoptosis (Srinivasan et al. 1998). An increase in activated Caspase 3 was seen in the ventricular neuroepithelium of $c a B m p r-1 b$ embryos at all ages measured between E9.5 and E12.5 compared with wild-type embryos (Fig. 5I-P). This increase was widespread but most prominent in the forebrain and hindbrain. No enhanced cell proliferation was seen at any age analyzed (Figs. 6M, 7S). In addition, dorsoventral identity was not altered, as measured by Pax6, Pax7, and Wnt1 expression (Fig. 6E-H; data not shown). Staining of E11.5 embryos for the 160-kD subunit of neurofilament $\left(\mathrm{NF}_{160} ;\right.$ Fig. 6I,J) showed no evidence of increased neuronal differentiation. Islet1 staining, which identifies early differentiating dorsal interneurons and ventral motorneurons (Jurata et al. 2000), was also unaffected (Fig. $6 \mathrm{~K}, \mathrm{~L})$. Therefore, the principal early response to caBmpr$1 b$ was apoptosis.

\section{Differentiation is a later response to BMPR-IB activation}

By E13.5, cells in caBmpr-1b embryos were disorganized and spilled from the dorsal and ventral roots of the spinal cord (Fig. 7A,B). At high magnification (data not shown), individual cells were observed spanning the glia limitans, suggesting that a chemotropic response was causing cell migration. Among the closest cell types to the dorsal and ventral roots are the two postmitotic Islet $1^{+}$ cell groups, one marking dorsal interneurons and the other marking ventral motorneurons (Jurata et al. 2000). Antibody staining revealed that Islet $1^{+}$cells were ectopically located along the dorsal and ventral roots and were also scattered throughout the spinal cord (Fig. $7 \mathrm{P}, \mathrm{Q})$. These cells could be distinguished from Islet ${ }^{+}$ cells of the dorsal root ganglia by having less intense staining.

Although E11.5 caBmpr-1b embryos showed no difference in BrdU labeling (Fig. 6M), by E13.5 the number of $\mathrm{BrdU}^{+}$cells decreased, suggesting that terminal differentiation occurred (Fig. 7S). The strongest phenotype showed a twofold decrease in BrdU ${ }^{+}$cells, which correlated with a stronger migratory response and more severe exencephaly. Likewise, staining was reduced or eliminated for the pan-neural precursor marker nestin (Fig. 7E), as well as Pax7 (Fig. 7H), and Pax6 (Fig. 7K), indicating that both dorsal and ventral precursors were differentiating. Staining for $\mathrm{NF}_{160}$ showed wider and more scattered expression in transgenic embryos (Fig. 7N). Large bundles of $\mathrm{NF}_{160}{ }^{+}$fibers could be seen leaving both the dorsal and ventral roots, suggesting that large numbers of cells were differentiating into neurons and their processes exiting the spinal cord. An increase in the number of Islet ${ }^{+}$cells was also seen (Fig. 7Q), indicating that mid-gestation precursors prematurely differentiated into early neuronal types.

\section{Evidence of a link between receptor actions}

There was genetic evidence of a link between the BMPRIA and BMPR-IB pathways based on certain phenotype 


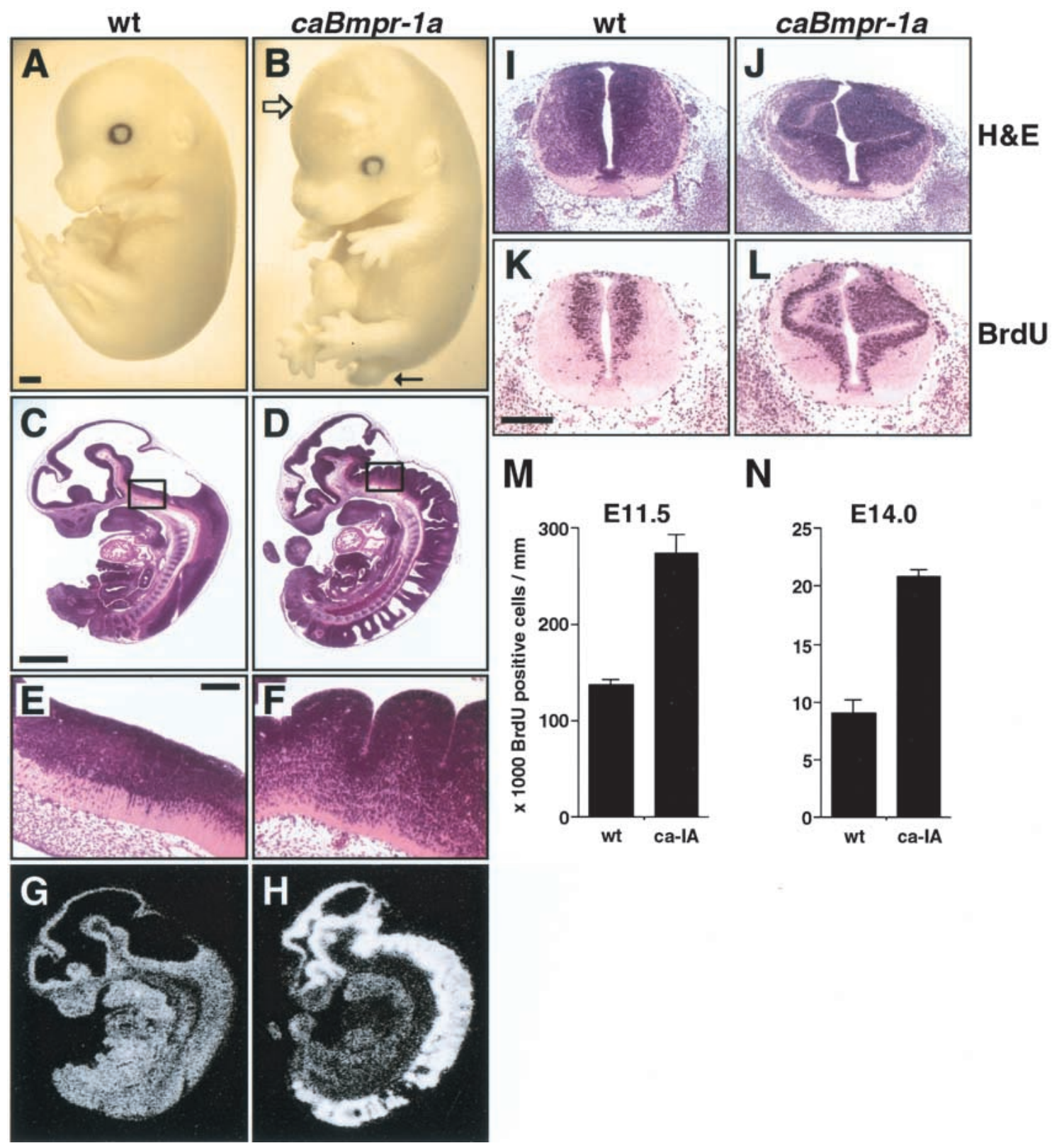

Figure 2. Excess proliferation in early neural tube in caBmpr-1a transgenic embryos. $(A, B)$ Whole mount images at E15.5 show wild type versus pNERV.caBmpr-1a embryos; note the slight distortion of the cranium (open arrow) and the truncated tail (arrow). (C,D) Sagittal sections through E11.5 wild-type and caBmpr-1a embryos; note the extensive neuroepithelial gyrification in the transgenic embryos. (E,F) Higher (200×) magnification of hindbrain (box in $C$ and $D)$. $(G, H)$ Bmpr-1a mRNA expression in wild-type and caBmpr$1 a$ transgenic embryos shown in $C$ and $D$. $(I-L)$ Transverse sections showing hematoxylin and eosin and bromodeoxyuridine (BrdU) staining in E11.5 wt and caBmpr-1a transgenic embryos. $(M, N)$ Bar graph indicating numbers of BrdU ${ }^{+}$cells per unit spinal cord length in wild-type versus caBmpr-1a embryos at E11.5 and E14.0; $P<0.01$. Bars: $A-D, G, H, 1 \mathrm{~mm} ; E, F, I-L, 200 \mu \mathrm{m}$.

similarities at early and mid-gestation. Activated Caspase 3 was also increased in early caBmpr-1a embryos in the thinning forebrain neuroepithelium (data not shown), but unlike caBmpr-1b transgenics, these embryos had complete neural tube closure and normal craniofacial structure (Table 1; Fig. 2). This suggested that apoptosis occurred as a delayed response to BMPR-IA activation.

By E14.0, caBmpr-1a embryos also showed a migratory and differentiative response (Table 1; Fig. 7). However, comparison of the two transgenics at mid-gestation indicated that although caBmpr-1b showed only a differentiative response (Fig. 7), caBmpr-1a embryos still showed increased proliferation (Fig. $2 \mathrm{~N}$ ) as well as increased neuronal differentiation (Fig. 7O,R). Thus, dorsal instruction and proliferation were seen only in caBmpr$1 a$ embryos, but apoptosis and differentiation were seen in both transgenics. This suggested that BMPR-IB acts downstream of BMPR-IA. 


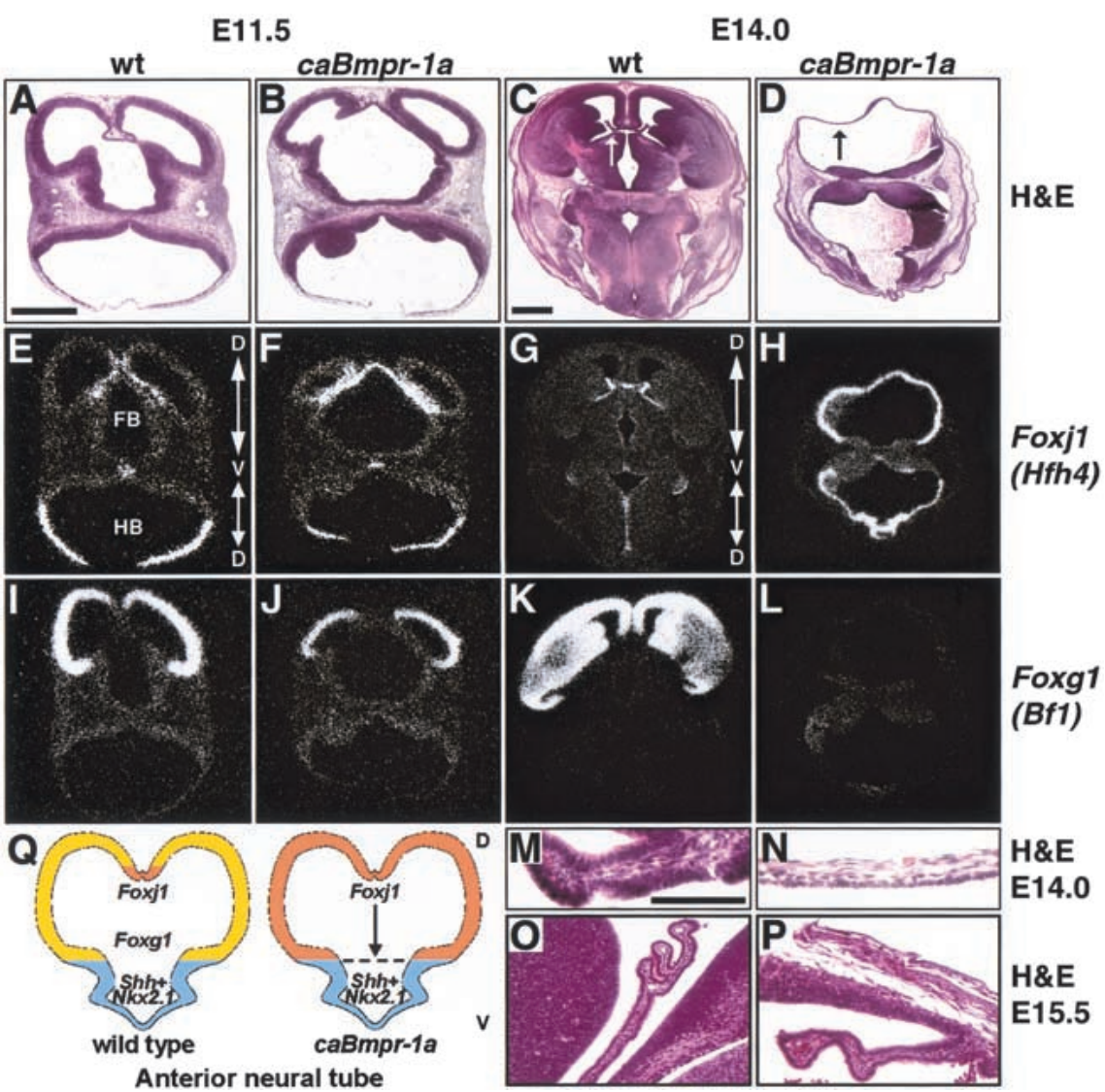

Figure 3. Dorsalization of anterior neural tube in caBmpr-1a transgenic embryos. $(A, B)$ Hematoxylin and eosin staining of E11.5 wild-type forebrain and hindbrain versus caBmpr-1a embryo with mild holoprosencephaly; transgene expression is shown in Figure 1D. $(C, D)$ $\mathrm{H} \& \mathrm{E}$ staining of E14.0 wild-type forebrain and hindbrain versus caBmpr-1a holoprosencephalic neural tube; transgene expression is shown in Figure 1D. Compare the normal choroid plexus epithelium (white arrow in $C$, magnified in $M)$ in wild-type embryo with the similar thin cuboidal epithelium (black arrow in $D$, magnified in $N$ ) of caBmpr-1a transgenic. $(E, F)$ Foxj1 in situ hybridization on E11.5 wild-type and caBmpr-1a forebrain and hindbrain, showing expanded expression in the telencephalon and dorsal diencephalon of the transgenic embryo. Arrows mark orientation of dorsal-ventral axis. $(G, H)$ Foxi1 in situ hybridization of E14.0 wild-type and caBmpr-1a forebrain and hindbrain, showing a complete of expansion of Foxj1 expression throughout the dorsal forebrain in transgenic embryo. $(I, J)$ Foxg1 in situ hybridization of E11.5 wild-type and caBmpr-1a forebrain and hindbrain, showing diminished expression in transgenic embryo. $(K, L)$ Foxg1 in situ hybridization of E14.0 wildtype and caBmpr-1a forebrain and hindbrain, showing complete loss of expression in transgenic embryo. $(M, N)$ Higher $(200 \times)$ magnification of area labeled by arrows in $C, D$. $(O, P)$ High $(200 \times)$ magnification of E15.5 wild-type choroid plexus $(O)$ and ectopic choroid-like structure in caBmpr-1a embryo $(P)$. (Q) Graphic summarizing the results of Figure 3. Activation of BMPR-IA results in the expansion of the dorsal-most domain (expressing Foxi1) at the expense of less-dorsal domains (expressing Foxg1), whereas ventralizing signal(s) prevent the dorsalization of the most ventral domain (Shh/Nkx2.1 based on data from Golden et al. 1999). Bars: A,B,E,F,I,J, $1 \mathrm{~mm} ; C, D, G, H, K, L, 1 \mathrm{~mm} ; M-P, 100 \mu \mathrm{m}$.

\section{$B M P R-I B$ expression is induced by BMPR-IA activation and repressed by Shh}

Two other sets of evidence suggested that the actions of BMPR-IA and BMPR-IB are linked. First, in situ hybridization revealed that although Bmpr-1a is expressed ubiquitously among neural precursors at all gestational ages (Fig. 1A), Bmpr-1b is expressed only after E8.75 and is restricted to dorsal neural precursors (Fig. 1B; Dewulf et al. 1995) surrounding the source of BMP ligands (Furuta et al. 1997). Second, the domain of Bmpr-1b expression expanded ventrally in some caBmpr-1a transgenic embryos (Fig. 8A). The hypothesis most consistent with these observations is that activation of BMPR-IA induces or stabilizes Bmpr-1b expression in precursor cells, and subsequent BMPR-IB activation is responsible for the death or differentiation of these cells.

We tested this hypothesis by measuring BMP responses in dissociated stem cells from E12 rat ventral midbrain (VM; Fig. 8B; Studer et al. 1998), a region that does not normally express $B m p r-1 b$ or dorsal identity genes. We measured the expression of Bmpr-1b, which is normally restricted to the dorsal two thirds of the neural tube, and the expression of Msx1, which is induced by BMP treatment (Bendall and Abate-Shen 2000) but re- stricted to the dorsal-most domain in the spinal cord and forebrain (Grove et al. 1998; Bang et al. 1999). Treatment of VM stem cells with $5 \mathrm{ng} / \mathrm{mL}$ BMP2 resulted in an induction of both $B m p r-1 b$ and $M s x 1$ expression within $2 \mathrm{~h}$ (Fig. 8C). In contrast, Bmpr-1a expression was present in untreated VM stem cells and remained unchanged after BMP2 treatment (Fig. 8C), consistent with its ubiquitous expression in vivo. The induction of $B m p r-1 b$ and Msx1 was transient and began to decline after 8 to $24 \mathrm{~h}$. Both Bmpr-1b and Msx1 were induced by BMP2 in a dose-dependent manner (Fig. 8D). The actions of BMP2 were inhibited by Sonic hedgehog (Shh), a ventralizing factor that is expressed in the notochord and floor plate (Briscoe and Ericson 1999). Conversely, inhibiting Shh activity with cyclopamine (Cooper et al. 1998) promoted Bmpr-1b and Msx1 induction (Fig. 8E). Thus, BMPR-IA activation induces (and Shh represses) Bmpr-1b expression in the manner of a dorsal identity gene.

Bmpr-1b induction correlates with the onset of terminal differentiation in vitro

We then tested the effects of BMP signaling on stem cell proliferation and fate choice. We first measured BrdU 


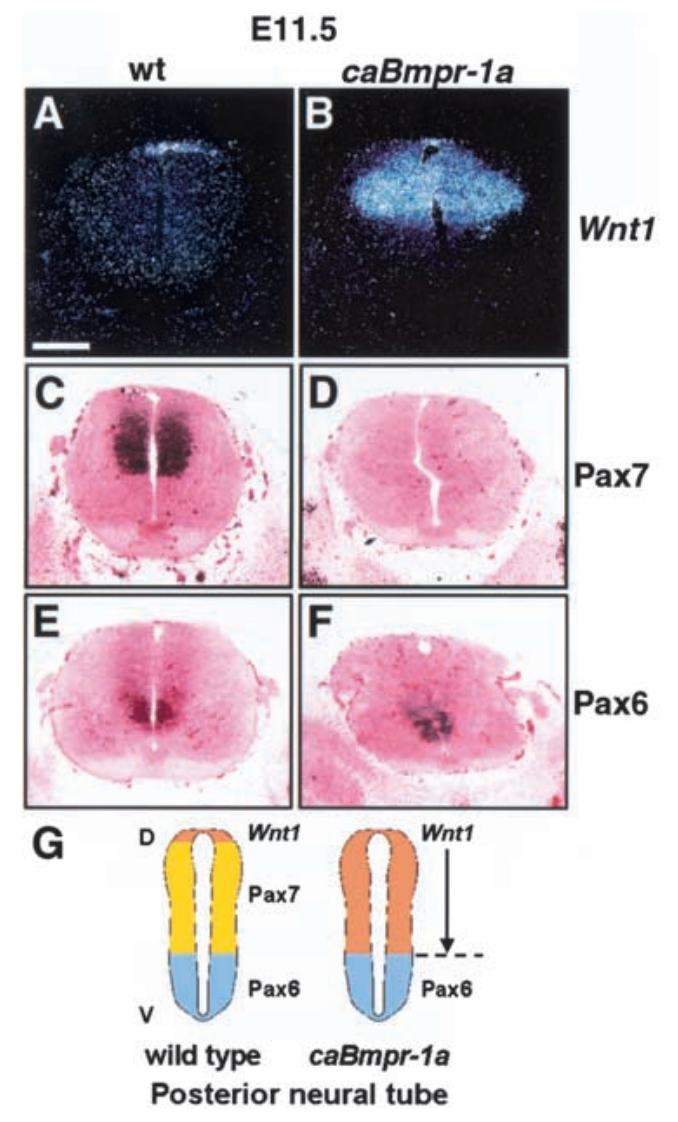

Figure 4. Dorsalization of posterior neural tube in caBmpr-1a transgenic embryos. Thoracic level of E11.5 to E12.0 spinal cord. $(A, B)$ Wnt1, which marks the roof plate and dorsal commissural precursors, has an expanded expression domain in caBmpr-1a embryos (moderate copy number). (C,D) Pax7, which marks the dorsal spinal cord exclusive of the dorsal-most domain in mice $(C)$, is diminished in caBmpr-1a embryos $(D)$. $(E, F)$ Pax6, which is expressed ventrally $(E)$, is unaffected in caBmpr-1a embryos $(F)$. (G) Graphic summarizing the results of Figure 4; see legend of Figure 3Q. Bar, $200 \mu \mathrm{m}$.

incorporation in E12 rat VM stem cells and found that low doses of BMP2 rapidly promoted proliferation (Fig. 9A), whereas higher doses had the opposite effect (Fig. 9B). To assay the instructive and differentiative effects of BMPs, we looked at the induction of neural crest, a dorsal precursor cell that emigrates from the neural tube to generate the peripheral nervous system, smooth muscle, and other cell types (Garcia-Castro and Bronner-Fraser 1999). Previous studies have shown that BMP treatment of cultured cortical, striatal, and spinal CNS stem cells efficiently changes their fate to neural crest (Mujtaba et al. 1998; Molne et al. 2000; T.G. Hazel, D.M. Panchision, M.H. Sailer, and R.D. McKay, unpubl.). We measured the generation of the postmitotic neural crest-derivative smooth muscle, as measured by the expression of smooth muscle $\alpha$-actin (SMA; Shah et al. 1996; Tsai and McKay 2000). Low doses of BMP2 were insufficient to generate smooth muscle, whereas higher doses effectively generated smooth muscle (Fig. 9C). The BMP2 doses causing terminal differentiation (Fig. 9B,C) correlated with the doses that induced Bmpr-1b (Fig. 8D,E). These results suggest that BMP2 causes proliferation through BMPR-IA until a threshold of Bmpr-1b induction is reached, after which cells undergo terminal differentiation.

\section{BMPR-IA and BMPR-IB act sequentially}

To test the hypothesis that the two BMP receptors act sequentially, we transfected cortical stem cells (Johe et al. 1996) with pNERV-driven mutant receptor constructs. We measured neural crest precursors by expression of $\mathrm{p} 75^{\mathrm{NGFR}}$ (Morrison et al. 1999), differentiated neural crest progeny by expression of SMA, and mitotically arrested cells by expression of $\mathrm{p} 21^{\mathrm{cip} 1}$, a cyclin-dependent kinase inhibitor (Jernvall et al. 1998). In nontransfected or mock-transfected conditions, cultures were composed of nestin ${ }^{+}$stem cells, with no staining for these markers or markers of any other cell types (data not shown). Stem cells transfected with caBmpr-1a initially expressed p75 NGFR (Fig. 10A,E) but later expressed SMA (Fig. 10C,F) as well as p21 $1^{\text {cip } 1}$ (Fig. 10C,G). This indicated that caBmpr-1a dorsalized cortical stem cells to neural crest precursors and then terminally differentiated these cells to smooth muscle. In contrast, stem cells transfected with caBmpr-1b expressed only p2 $1^{\text {cip } 1}$ (Fig. 10D,G), indicating that they had undergone mitotic arrest without prior dorsalization to the neural crest fate. Interestingly, the nuclei of $\mathrm{p} 21^{+} / \mathrm{SMA}^{+}$cells in caBmpr-1a transfected cultures had a characteristic large oval shape, whereas $\mathrm{p} 21^{+}$nuclei of caBmpr-1b transfected cells were small and indistinguishable from the p $21^{-}$nuclei of undifferentiated surrounding cells (Fig. 10C,D).

Stem cells cotransfected with both caBmpr-1a and dnBmpr-1b expressed the neural crest precursor marker p $75^{\text {NGFR }}$ but did not generate postmitotic smooth muscle (Fig. 10E-G), indicating that $d n B m p r-1 b$ blocked terminal differentiation. Stem cells cotransfected with both $d n B m p r-1 a$ and $c a B m p r-1 b$ were indistinguishable from caBmpr-1b transfected cells alone (Fig. 10E-G), indicating that blocking BMPR-IA function did not prevent BMPR-IB from causing mitotic arrest. These results support the conclusion that initial instruction and proliferation are mediated by BMPR-IA, subsequent mitotic arrest is mediated by $\mathrm{BMPR}-\mathrm{IB}$, and these receptors are sequentially linked.

\section{Discussion}

\section{A model for BMP signaling during neural development}

In this study we show that the expression patterns of two type I BMP receptors reflect their distinct functions in CNS development. Bmpr-1a is expressed early and ubiquitously in precursor cells (Fig. 1A). We found that BMPR-IA activation dorsalized and promoted proliferation of CNS precursor cells in vivo (Figs. 2-4) and in vitro 

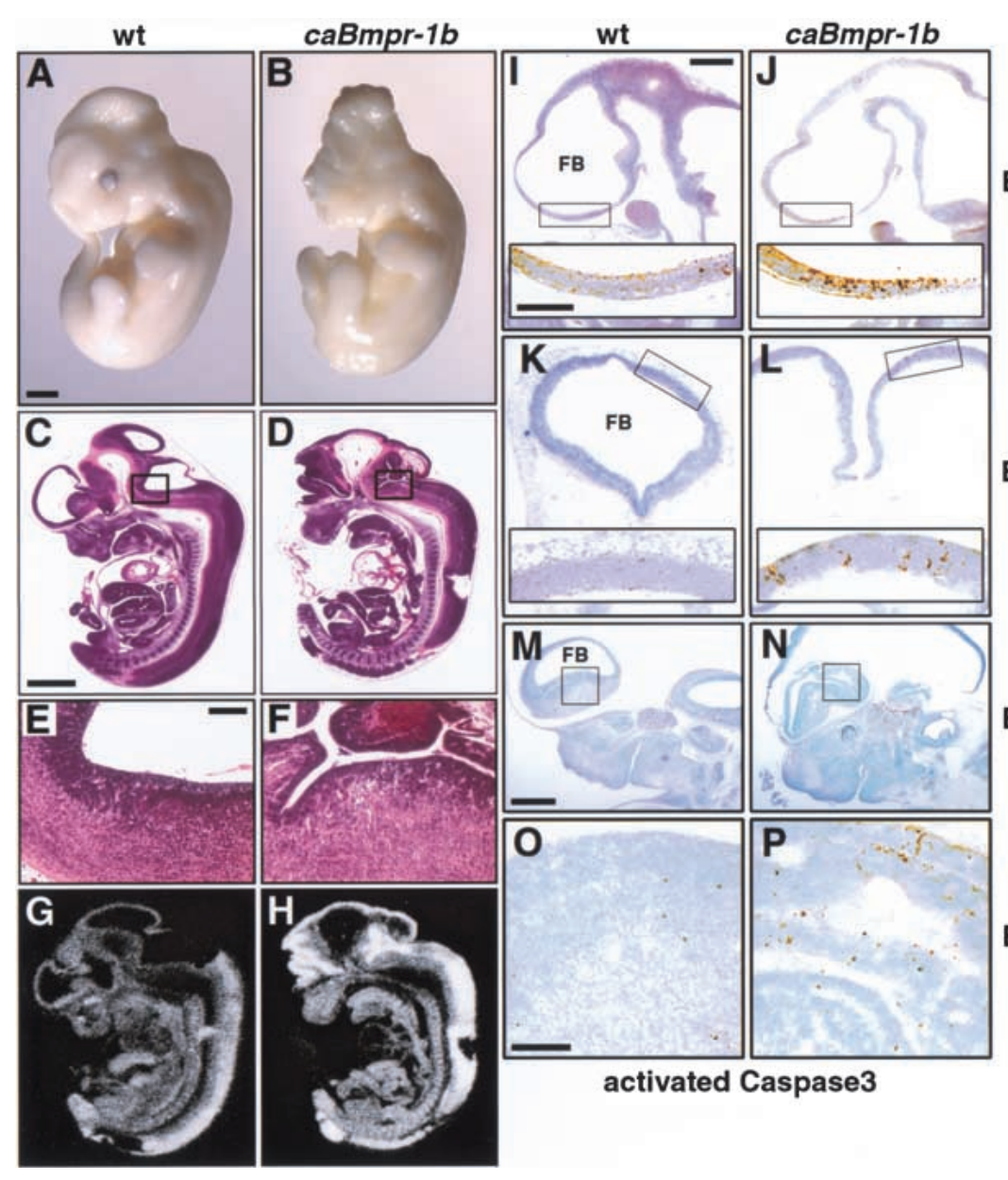

Figure 5. Apoptosis in early gestation caBmpr-1b transgenic embryos. $(A, B)$ Whole-mount images at E11.5 show the normally closed neural tube in wild-type embryos versus exencephaly and severe craniofacial defects in pNERV.caBmpr-1b embryos. $(C, D)$ Sagittal section through E12.5 wild-type and caBmpr-1b embryos shows that in transgenic embryos the neural tube is opened and folded back; hematomas are often present in associated vasculature. $(E, F)$ Higher magnification of boxed area in $C, D .(G, H) B m p r-1 b$ mRNA expression in wild-type and $c a B m p r-1 b$ transgenic embryos shown in $C, D$. $(I-P)$

E11.0 Forebrain staining for the activated proteolytic fragment of Caspase 3 in wild-type and caBmpr-1b embryo. At E9.5 (I, $)$; sagittal section, low copy number, c.n.), an enhanced level of activated Caspase 3 is seen in caBmpr-1b embryos preceding gross morphological defects; boxed area of forebrain is magnified to show labeled cells in inset. At E11.0 $(K, L$; transverse section, moderate c.n.), activated Caspase3 levels remain high in caBmpr-1b embryos as neural tube opening is observed in some areas. By E12.5 $(M, N$; sagittal section, moderate c.n.), high levels of activated

E12.5 Caspase3 in caBmpr-1b embryos are accompanied by neural tube collapse or complete exencephaly. $(O, P)$ Higher $(200 \times)$ magnification of ganglionic eminence labeled by box in $M$ and $N$. Bars: $A-D, G, H, 1$ $\mathrm{mm} ; E, F, 200 \mu \mathrm{m} ; I-L, 200 \mu \mathrm{m}$ (low magnification); $I-L$ (insets), $O, P, 100 \mu \mathrm{m} ; M, N$, $500 \mu \mathrm{m}$.
(Figs. 9 and 10). In contrast, Bmpr-1b is expressed only after E8.75 and is dorsally restricted (Fig. 1B). We found that BMP2 treatment and BMPR-1A activation induced the expression of Bmpr-1b in ventral $\left(B m p r-1 a^{+}, B m p r-\right.$ $1 b^{-}$) precursor cells (Fig. 8), which may account for its delayed and restricted expression during embryogenesis. BMPR-IB activation caused apoptosis in early gestation embryos (Fig. 5) and accelerated differentiation of precursor cells to neurons at mid-gestation (Fig. 7). Apoptosis and terminal differentiation were also seen in caBmpr-1a transgenic mice, suggesting that BMPR-IB functions downstream of BMPR-IA. This hypothesis was confirmed by in vitro experiments. First, ventral $\left(B m p r-1 a^{+}\right.$, $B m p r-1 b^{-}$) precursor cells showed increased proliferation at low BMP2 doses that minimally induced $B m p r-1 b$ expression (Figs. 8 and 9A). Second, these same cells differentiated at higher doses that caused maximal Bmpr-1b induction (Figs. 8 and 9B,C). Third, activating BMPR-IA while blocking BMPR-IB induced dorsal precursors that did not differentiate, yet activating BMPR-IB while blocking BMPR-IA yielded mitotically arrested cells that were not dorsalized (Fig. 10E-G).

Expression of caBmpr-1a transformed the anterior alar neural tube to Foxj $1^{+}$choroid plexus precursors (Fig. 3) and transformed the posterior alar neural tube to $\mathrm{Wnt} 1^{+}$ roof plate or dorsal commissural precursors (Fig. 4). This suggests that reports of BMP-induced holoprosencephaly (Golden et al. 1999) and Foxg1/Bf1 repression (Furuta et al. 1997) can be grouped with BMP-induced dorsalization of posterior neural precursors (Liem et al. 1995, 1997; Nguyen et al. 1998, 2000; Barth et al. 1999; Nikaido et al. 1999) as inducing effects of BMPR-IA activation. Likewise, the apoptosis and terminal differentiation seen in acute BMP application studies in cortex (Furuta et al. 1997; Li et al. 1998) and in stem cell culture (Kalyani et al. 1998; Zhu et al. 1999; Mehler et al. 2000) can be collectively viewed as terminating effects of BMPR-IB activation. Although the noggin ${ }^{-1}$ (McMahon et al. 1998) and caBmpr-1b embryos both display exencephaly, the noggin ${ }^{-/}$chordin $^{-/-}$double mutant has a phenotype more similar to early caBmpr-1a transgenics, including holoprosencephaly (Bachiller et al. 2000). Dissociated CNS stem cells can respond to BMPs by generating neural crest progeny (Mujtaba et al. 1998; Molne et al. 2000; T.G. Hazel, D.M. Panchision, M.H. Sailer, and R.D. McKay, unpubl.). Our results show that this is caused by the dorsalizing actions of BMPR-IA followed by the differentiative actions of BMPR-IB (Fig. 10). 


\section{E11.5}
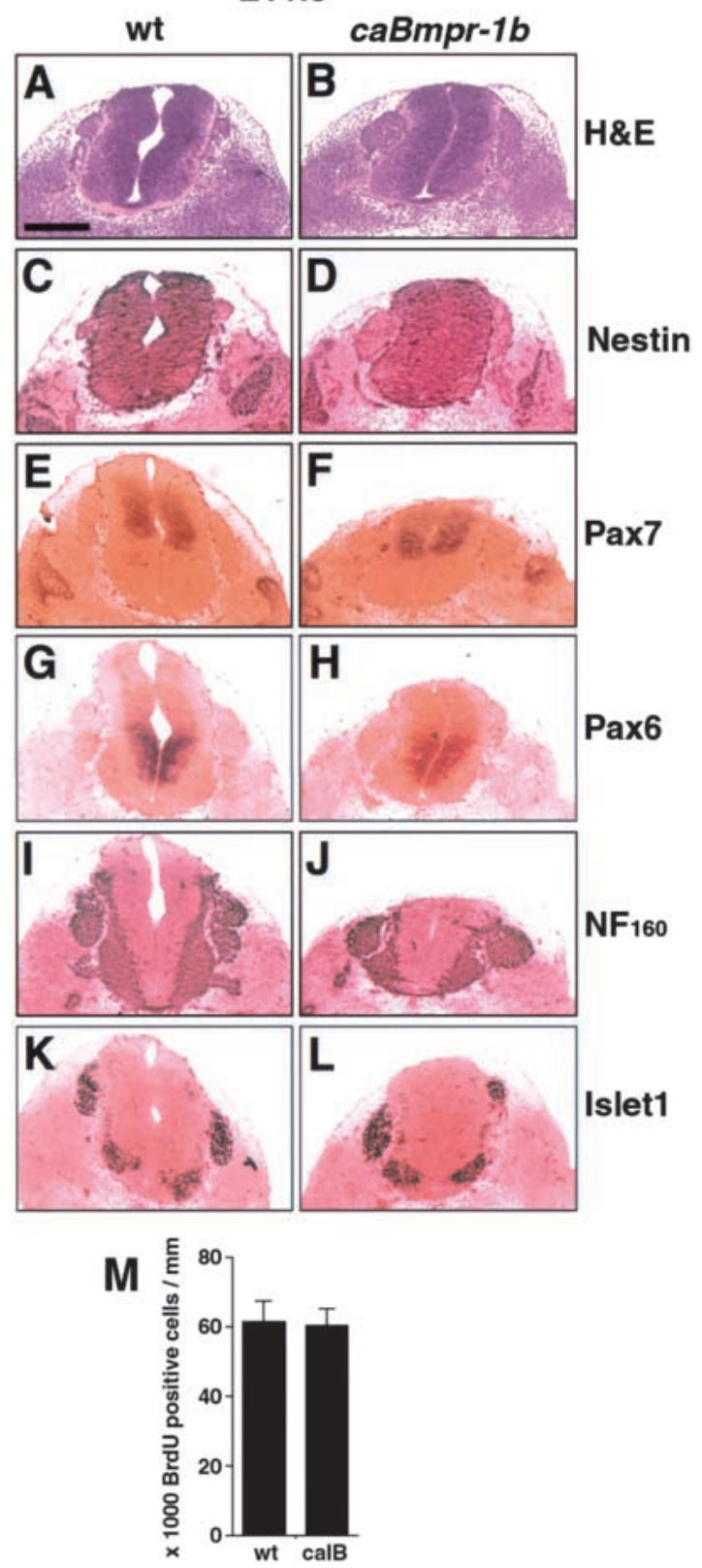

Figure 6. Lack of terminal differentiation in early gestation caBmpr-1b transgenic embryos. Lumbar level of E11.5 spinal cord. $(A, B)$ hematoxylin and eosin staining shows well-defined boundaries in wild-type embryos and caBmpr-1b embryos (moderate copy number). Note collapsed ventricular lumen in $c a B m p r-1 b$ embryo, similar to that seen in anterior neural tube (Fig. 5). (C-L) Staining with markers of precursor cells such as nestin, Pax7, and Pax6 shows no change in precursor identity or dorsoventral patterning. Staining with the differentiated cell markers $\mathrm{NF}_{160}$ and Islet1 shows no change. $(M)$ Bar graph indicating no change in numbers of $\mathrm{BrdU}^{+}$cells per unit spinal cord length in wild-type versus caBmpr-1b embryos at E11.5. Bar, $200 \mu \mathrm{m}$.

These results lead us to propose a model for BMP actions on neuroepithelial precursors during development (Fig. 11). An early, unpatterned precursor responds to
BMPs through the actions of BMPR-IA, which is expressed ubiquitously among precursor cells from gastrulation onward. Activation of BMPR-IA induces the expression of dorsal identity genes, including $B m p r-1 b$, and promotes the proliferation of this dorsalized cell. As cell surface levels of accumulating BMPR-IB exceed those of BMPR-IA, BMPs then cause a termination response of cell death or cell differentiation. The in vitro results indicate that a single BMP ligand can drive this feed-forward, self-limiting process (Figs. 8 and 9) and suggest that the dose of BMPs determines the rate at which it occurs.

\section{Alternative BMP pathways have opposing actions on cell number}

Our study shows that BMPR-IA and BMPR-IB mediate antagonistic drives: an initial one that instructs precursor cells and expands their numbers, and a final one that limits the numbers of that cell type. Previous studies support a proliferative role for BMP ligands and BMPRIA. Application of BMP7 causes proliferation in the ventral hindbrain (Arkell and Beddington 1997), consistent with the expression of Bmpr-1a but not Bmpr-1b in this region. Mice that lack Bmpr-1a die before gastrulation partially because of a proliferation defect; in these animals, total cell number in the epiblast is reduced by $20 \%$ to $30 \%$, and primitive streak formation is not initiated (Mishina et al. 1995). In chick limb bud, BMPR-IA activation delays chondrocyte differentiation whereas BMPR-IB activation promotes apoptosis or chondrocyte condensation (Zou et al. 1997). Mice that lack functional $B m p r-1 b$ in the limb have complex defects, including incomplete distal limb differentiation (Zou et al. 1997; Baur et al. 2000; Yi et al. 2000). Interestingly, the targeted Bmpr-1 $b^{-1-}$ mouse has no obvious reported neural defects (Yi et al. 2000), suggesting that redundant mechanisms exist to promote terminal differentiation.

The proliferation of vertebrate limb muscle precursors is promoted by low doses of BMPs, acting through Pax3. At higher doses, BMPs promote repression of Pax3 and terminal differentiation (Amthor et al. 1998, 1999). This is consistent with the dose-dependent BMP stimulation of proliferation and terminal differentiation we see in our assays (Fig. 9A-C). It also suggests that the increase in proliferation by $6 \mathrm{~h}$ (Fig. 9A) depends first on the induction of dorsal patterning genes (e.g., Pax, Fox) through BMPR-IA. We show that terminal differentiation correlates with the induction of Bmpr-1b (Figs. 8CE, 9A-C). Ectopic Bmpr-1b expression has been reported in chick limb buds treated with TGF $\beta$ ligands (Merino et al. 1998, 1999) or infected with caBmpr-1a (Zou et al. 1997). Bmpr-1b repression is seen in limb buds treated with noggin (Pizette and Niswander 2000). Although the functional significance of these results is not established, they suggest that the sequential activation of BMP receptors may regulate precursor cell identity and number in other tissues.

We also observed that Bmpr-1b (and to a lesser extent 

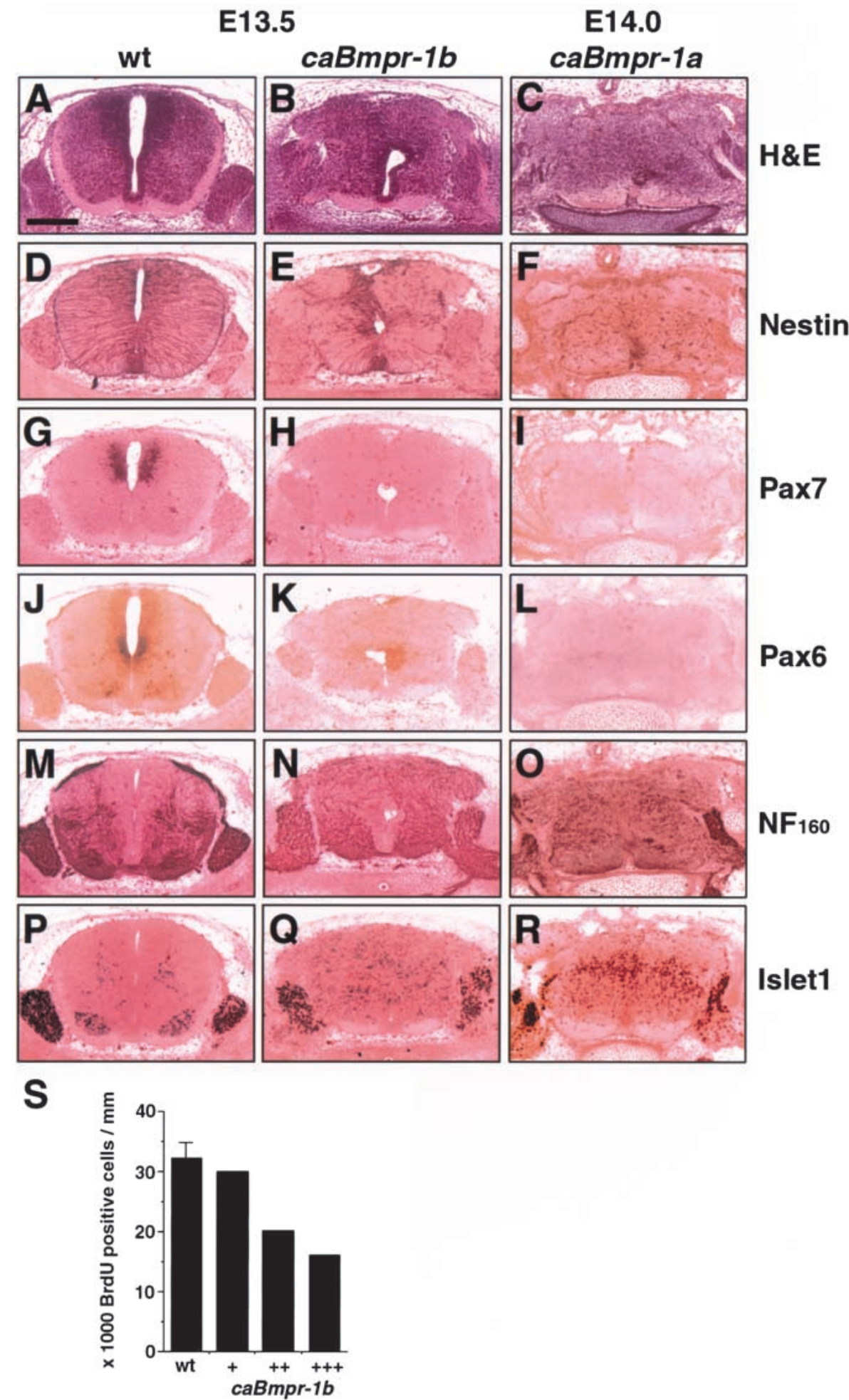

Figure 7. Terminal differentiation in mid-gestation transgenic embryos. Lumbar level of E13.5 wt, E13.5 caBmpr-1b (moderate copy number, c.n.) and E14.0 caBmpr-1a (high c.n.) spinal cord. $(A-C)$ Hematoxylin and eosin staining shows well-defined boundaries in wild-type embryos compared with loss of boundaries in both caBmpr-1b and caBmpr-1a embryos; note migratory response. (D-L) Staining with markers of precursor cells such as nestin, Pax7, and Pax6 show a reduction or elimination of staining in $c a B m p r-1 b$ and caBmpr-1a embryos. $(M-R)$ Staining with markers of differentiated cells such as $\mathrm{NF}_{160}$ and Islet 1 shows an increase in number and/or area of expression in $c a B m p r-1 b$ and $c a B m p r-1 a$ embryos. Note the migration of Islet $1^{+}$cells and the spreading of $\mathrm{NF}_{160}$-positive fibers throughout the spinal cord and out of the dorsal and ventral roots. $(S)$ Bar graph indicating numbers of BrdU ${ }^{+}$cells per unit spinal cord length in E13.5 wild-type versus caBmpr-1b embryos; variability between transgenic animals reflects variable penetrance of the phenotype. Bar, $200 \mu \mathrm{m}$. 

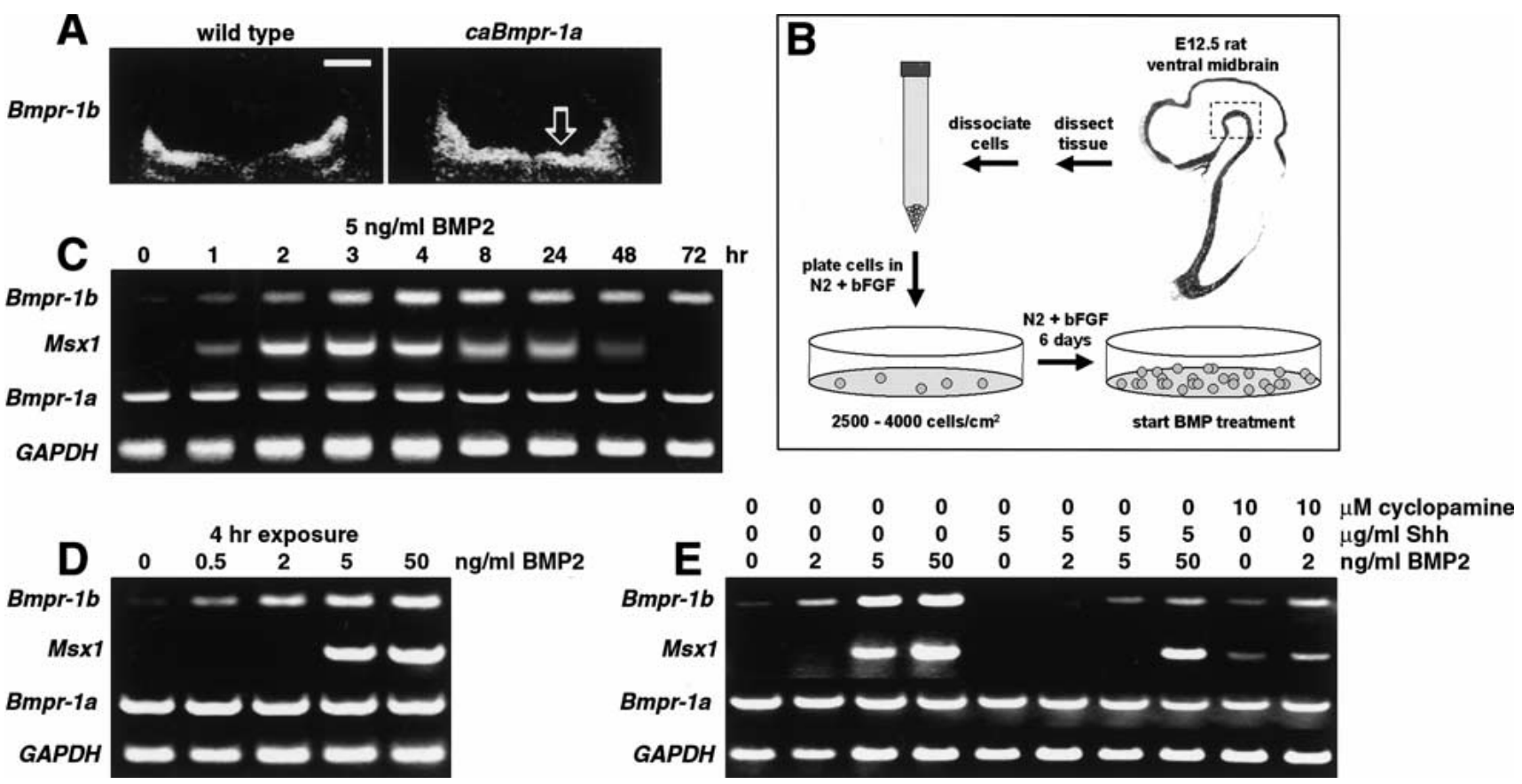

Figure 8. Induction of $B m p r-1 b$ expression by BMP2 and caBmpr-1a. (A) In situ hybridization for Bmpr-1b on transverse hindbrain sections of E11.5 wild-type and caBmpr-1a embryos; open arrow indicates ectopic Bmpr-1b expression in ventral hindbrain. $(B)$ Diagram showing isolation and culturing of E12.5 rat ventral midbrain (VM) stem cells. (C) RT-PCR of E12.5 VM stem cells showing induction of $B m p r-1 b$ and $M s x 1$ within 2 to $4 \mathrm{~h}$ of treatment with $5 \mathrm{ng} / \mathrm{mL}$ BMP2; Bmpr-1a and GAPDH expression are unchanged. $(D)$ Induction of Bmpr-1b and Msx1 by rtPCR in E12.5 VM stem cells after 4-h treatment with varying doses of BMP2. (E) Induction of Bmpr-1b and Msx1 at $4 \mathrm{~h}$ is inhibited by Shh cotreatment; inhibition of Shh by cyclopamine promotes induction of $B m p r-1 b$ and Msx1. Bar, $500 \mu \mathrm{m}$.

Bmpr-1a) expression is paradoxically lower near the immediate source of BMPs (Fig. 1A,B). This may be because of accelerated apoptosis or terminal differentiation of cells in regions of highest BMP activity (Fig. 9), resulting in a loss or down-regulation of the receptors (Fig. 11). Alternatively, in Drosophila the highest Dpp levels negatively regulate expression of the receptor thick veins $(t k v)$ to control the range of the Dpp gradient (Lecuit and Cohen 1998; Teleman and Cohen 2000; Entchev et al. 2000). If a similar mechanism operates in mammals, then Bmpr-1b expression would be both positively (Fig. 8) and negatively regulated by BMP ligands.

An intriguing question is how the distinct BMPR-IA and BMPR-IB signals are transduced inside the cell. There is no evidence to date that differential activation of Smad1/5/8 proteins can account for the distinct actions of BMPs. TGF $\beta$ family ligands have been reported to also activate MAP kinases of the p38, p46/54 ${ }^{\mathrm{INK}}$, and $\mathrm{p} 42 / 44^{\mathrm{ERK}}$ families, but the evidence is contradictory about whether these responses are either direct or specific for such effects as mitogenesis or apoptosis (Hu et al. 1999; Iwasaki et al. 1999; Monzen et al. 1999; Nakamura et al. 1999; Yamaguchi et al. 1999; Kimura et al. 2000). Our results indicating that BMP actions can be classified as either inducing (through BMPR-IA) or terminating (through BMPR-IB) should provide defined cellular assays for identifying distinct intracellular signaling pathways.

\section{Modulation and inhibition of the BMPR-IB termination response}

We show that in early gestation embryos (before E12), caBmpr-1b caused mainly apoptosis (Fig. 5), as markers of patterning, proliferation, and differentiation remained unchanged (Fig. 6). However, as development proceeded, caBmpr-1b accelerated terminal differentiation of precursor cells (Fig. 7). This is consistent with our conclusion that BMPR-IB does not specify cell fate per se but instead mediates a generic terminal response by causing cell cycle arrest, leading to apoptosis or differentiation (Fig. 10B,D-G; Coffman and Studzinski 1999; Yoshikawa 2000).

These results suggest that additional competence signals are required to interpret the BMPR-IB termination response. BMP-treated precursors differentiate to a neuronal fate when neurogenin is expressed (Sun et al. 2001) but are directed to a glial fate when the Delta-Notch pathway is activated (Morrison et al. 2000). Changes in competence signal expression may explain why CNS stem cells in vitro show an age-dependent bias in their response to BMPs, ranging from apoptosis to neurogenesis and then gliogenesis (Gross et al. 1996; Mabie et al. 1999; Mehler et al. 2000; T.G. Hazel, D.M. Panchision, M.H. Sailer, and R.D. McKay, unpubl.).

We also show that as long as BMPR-IB expression was low or its activity blocked, BMP signaling maintained 

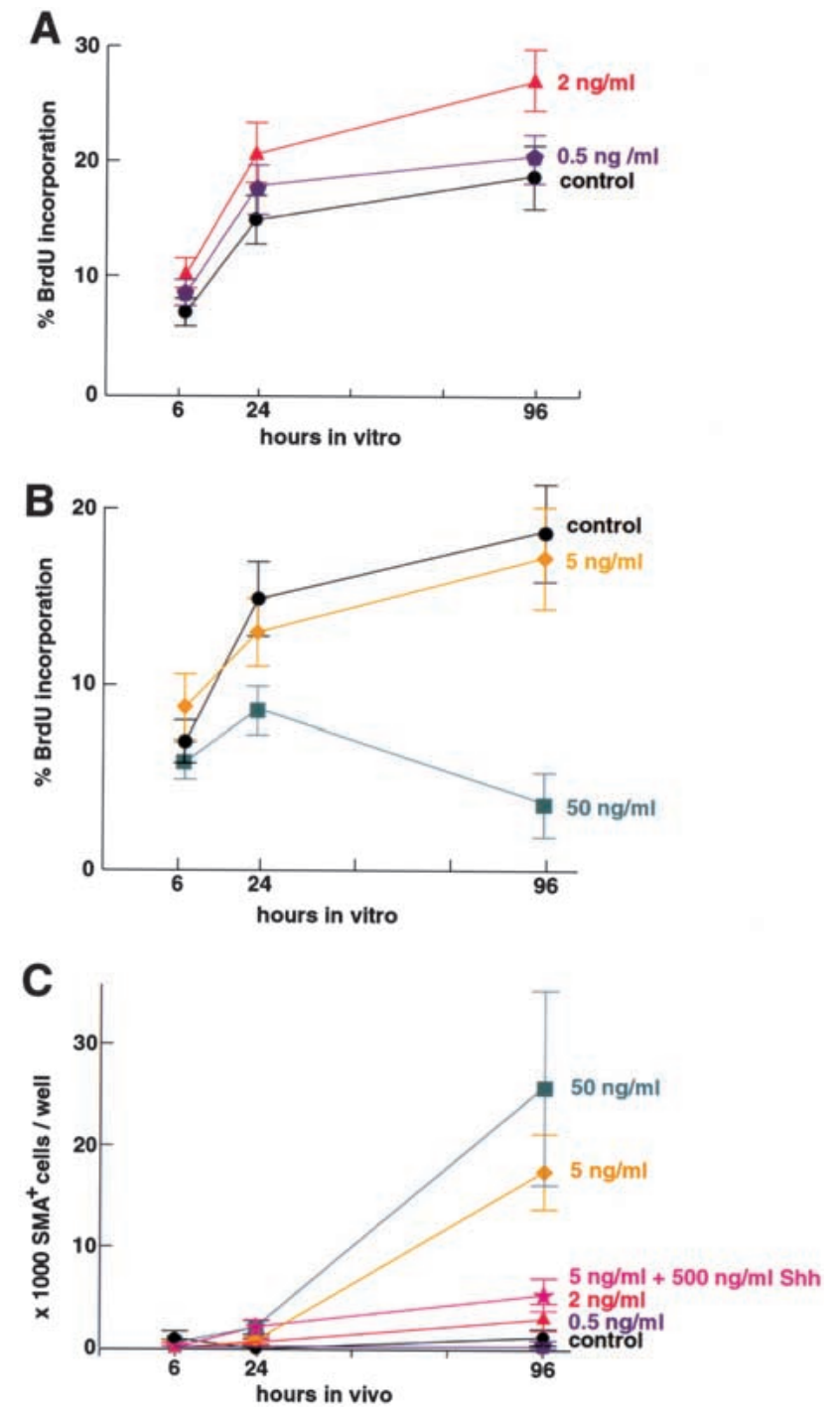

Figure 9. Dose-dependent control of precursor cell number and differentiation by BMP2. (A) Continuous treatment with low doses of BMP2 lead to increased percentage of bromodeoxyuridine-positive $\left(\mathrm{BrdU}^{+}\right)$E12.5 ventral midbrain (VM) stem cells. $\mathrm{BMP} 2$ at $2 \mathrm{ng} / \mathrm{mL}$ significantly increases percentage $\mathrm{BrdU}^{+}$cells at $6 \mathrm{~h}$ compared with control. $(B)$ Higher doses of BMP2 lead to decreased percentage of BrdU ${ }^{+}$E12.5 VM stem cells. (C) High doses of BMP2 cause both dorsalization and differentiation of E12.5 VM stem cells, as measured by smooth muscle $\alpha$-actin $(\mathrm{SMA})^{+}$cell number. Note that the doses causing terminal differentiation also cause maximal Bmpr-1b induction (see Fig. 8); $n=3$ for each experiment.

cells in a dorsal precursor state (Figs. 9 and 10). There is evidence to support negative control of the BMPR-IB termination response. Apoptosis can be blocked by survival factors like insulin, which activates a PI3 kinase/Akt pathway to prevent TGF $\beta$-mediated apoptosis /Chen et al. 1998). Differentiation may be blocked by mitogenic signals like EGF, which uses a p42/44 ${ }^{\mathrm{ERK}}$-mediated pathway to inhibit Smad activation (Kretzschmar et al. 1997). This would permit cell proliferation to continue despite
Sequential BMP receptor actions in neural development

the expression of BMPR-IB and would explain why the dorsal neural tube does not immediately differentiate once Bmpr-1b is induced (Fig. 1).

\section{Generality of the mechanism}

There is evidence that the feed-forward mechanism described here may also operate in invertebrates. In Caenorhabditis elegans, loss of function in the BMP receptor homolog sma-6 results in a small body phenotype (Krishna et al. 1999). The C. elegans BMP homolog dbl-1 also controls body size by regulating cell growth and/or proliferation (Suzuki et al. 1999). Loss-of-function mutations in Drosophila Dpp and its receptor $t k v$ result in patterning defects and decreased proliferation of wing imaginal disk precursors (Burke and Basler 1996; Edgar and Lehner 1996). These results suggest a BMPR-IA-like function for the invertebrate receptors. However, the $t k v$ mutant also has a later defect in differentiation (Burke and Basler 1996), suggesting that it activates a BMPR-IBlike pathway.

We show how sequential activation of BMP receptors allows BMP ligands to control precursor cell production and fate. This may be one way to regulate tissue identity and size during development (Day and Lawrence 2000). Such a mechanism could act as a built-in safeguard against unrestricted growth during tissue renewal or repair (Sakou 1998) and may be one of the regulatory processes disrupted in cancer (Ishidou et al. 1995; Yamada et al. 1996; Kim et al. 2000).

\section{Materials and methods \\ Construction of mutant type I BMPRs}

cDNAs encoding mutant forms of the BMP receptors were generated by PCR-mediated site-directed mutagenesis and/or were the kind gift of L. Niswander (Memorial Sloan Kettering Cancer Center, New York). The ca forms contain a Glu to Asp substitution in the GS domain (Q233D caBmpr-1a; Q203D caBmpr$1 b$ ) to mimic phosphorylation by the type II receptor (Zou et al. 1997). The dn forms were generated by a Lys to Arg substitution in the ATP-binding site of the kinase domain (K261R dnBmpr$1 a$; K231R dnBmpr-1b), which abolishes kinase activity (Zou et al. 1997). Mutant Bmpr-1a cDNAs were tagged at the C terminus with the synthetic Flag epitope; mutant Bmpr-1b cDNAs were tagged at the $\mathrm{C}$ terminus with the hemagglutanin (HA) epitope derived from the human influenza virus.

\section{Construction of expression vector}

A neuroepithelial expression/reporter vector (pNERV) was constructed using a 5359-bp genomic fragment containing the nestin basal promoter and a 653-bp genomic fragment of the conserved portion of the nestin second intron (Josephson et al. 1998) to confer neural precursor-specific expression of the BMP receptor mutants. The nestin promoter was ligated upstream of a splice donor/acceptor site, lacZ reporter gene and SV40 polyadenylation sequence derived from a CMV $\beta$ expression vector (Clontech). The nestin second intron fragment was ligated downstream of the polyadenylation site in a reverse orientation. The lacZ reporter gene contained flanking NotI sites to allow 

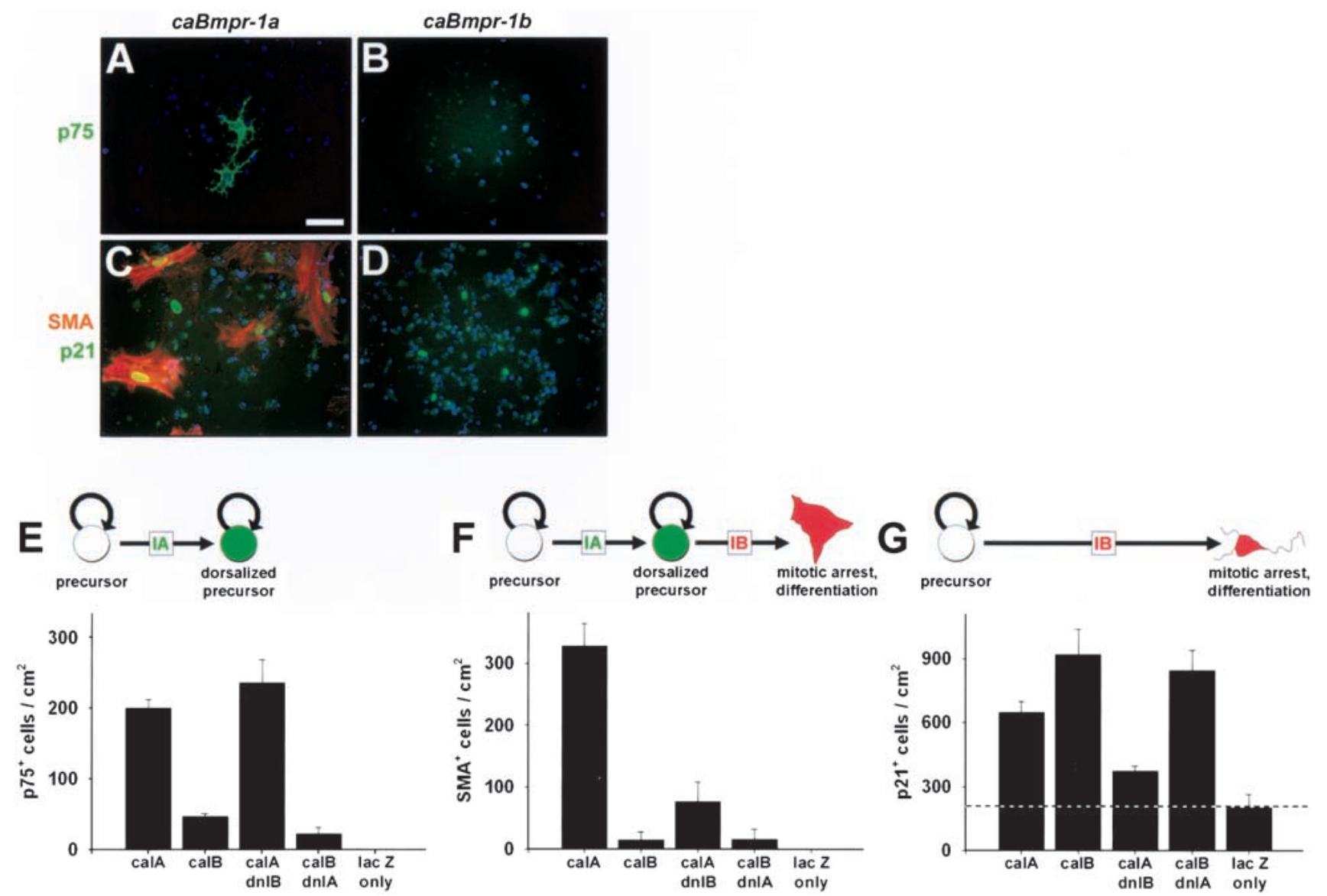

Figure 10. Sequential actions of bone morphogenetic protein $(\mathrm{BMP})$ receptors on dorsal precursor production and fate. $(A-D)$ Antibody staining for $\mathrm{p} 75^{\mathrm{NGFR}}$ (marking dorsalized precursors), smooth muscle $\alpha$-actin (SMA; dorsalized and differentiated), and p21 $1^{\text {cip } 1}$ (mitotic arrest) in caBmpr-1a or caBmpr-1b transfected cultures. $(E-G)$ Quantitation of $\mathrm{p} 75^{\mathrm{NGFR}}$, SMA, and $\mathrm{p} 21^{\text {cip1 }}$ staining in $D-G$ after transfecting E14.5 cortical stem cells with pNERV driving caBmpr-1a (caIA); caBmpr-1b (caIB); double transfection with caIA plus $d n I B$; caIB plus $d n I A$; or lacZ only. Actions of BMPR-IA and BMPR-IB can be dissociated, showing that BMPR-IA acts first to instruct precursor cells, while BMPR-IB acts later to terminally differentiate cells. Dotted line in $G$ marks baseline of $\mathrm{p} 21^{\text {cip } 1}$ staining caused by confluent cultures at the time of fixation; $n=3$ or 4 for each experiment. Bar, $A-D, 50 \mu \mathrm{m}$.

replacement of lacZ cDNA with Bmpr cDNAs. Staining for the $\beta$-galactosidase reporter in E11.5 to E15.5 mouse embryos indicated strong staining in the proliferative ventricular zone throughout the neural tube but not in the roof plate, floor plate, or prechordal plate (data not shown). No staining was seen in postmitotic mantle layers of the neural tube, consistent with previous studies (Josephson et al. 1998). Expression was detected in $94 \%$ of all embryos containing at least one transgene copy for any cDNA; ectopic expression was never observed.

\section{Generation of transient transgenic mice}

Transgenic mice were produced as described (Hogan et al. 1994). Mice used were C57Bl6 $\times$ C 3 H F1 embryo donors, $\mathrm{C} 57 \mathrm{Bl} 6 \times \mathrm{C} 3 \mathrm{H}$ F1 stud males, and ICR foster mothers. Integration of the transgene was assayed by yolk sac PCR and/or Southern blot analysis (Hogan et al. 1994) using the 653-bp nestin second intron fragment as a probe. Copy number could be estimated by comparing intensity of pNERV transgene band versus endogenous nestin second intron band on Southern blot (Fig. 1D,E). Embryos were staged on dissection; the day of transfer roughly corresponded to $0.5 \mathrm{~d}$ postcoitum.

\section{Histological analysis}

Embryos were fixed in Bouin's solution from 1 to 20 h, depending on the age of the embryo. Embryos were dehydrated in an ethanol series, clarified, and embedded in paraffin. Sections (10 $\mu \mathrm{m})$ were mounted on Superfrost/Plus microscope slides (Fisher). Slides were de-paraffinized, rehydrated, and, for routine morphological analysis, stained with hematoxylin and eosin (H\&E). For immunohistochemistry, slides were subjected to high-temperature antigen unmasking using $0.1 \mathrm{M}$ sodium citrate $(\mathrm{pH} 6.0)$ at $100^{\circ} \mathrm{C}$ for $10 \mathrm{~min}$, followed by a 15 -min cooling period. For peroxidase staining, slides were incubated in $0.1 \%$ hydrogen peroxide in PBS for $30 \mathrm{~min}$ to quench endogenous peroxidase and then were rinsed in distilled water. Blocking was performed with $1 \times$ PBS containing $5 \%$ normal goat serum (NGS) and $0.1 \%$ Triton X-100. Primary antibodies were used against nestin (McKay lab, rabbit 130), activated Caspase3 (Idun, CM1), Pax6 (gift of R. Reed, Johns Hopkins University, Baltimore, MD), Pax7 (DSHB), Islet1 (DSHB, clone 40.2D6), NF ${ }_{160}$ (Sigma N5264), smooth muscle $\alpha$-actin (Sigma A2547), p $75^{\text {NGFR }}$ (Calbiochem GR10), and $\mathrm{p} 21^{\text {cip } 1}$ (Calbiochem PC55). Primary antibodies were diluted in blocking solution and incubated on sections for 16 to $72 \mathrm{~h}$ at $4^{\circ} \mathrm{C}$. Sections were washed in $1 \times \mathrm{PBS}$ 

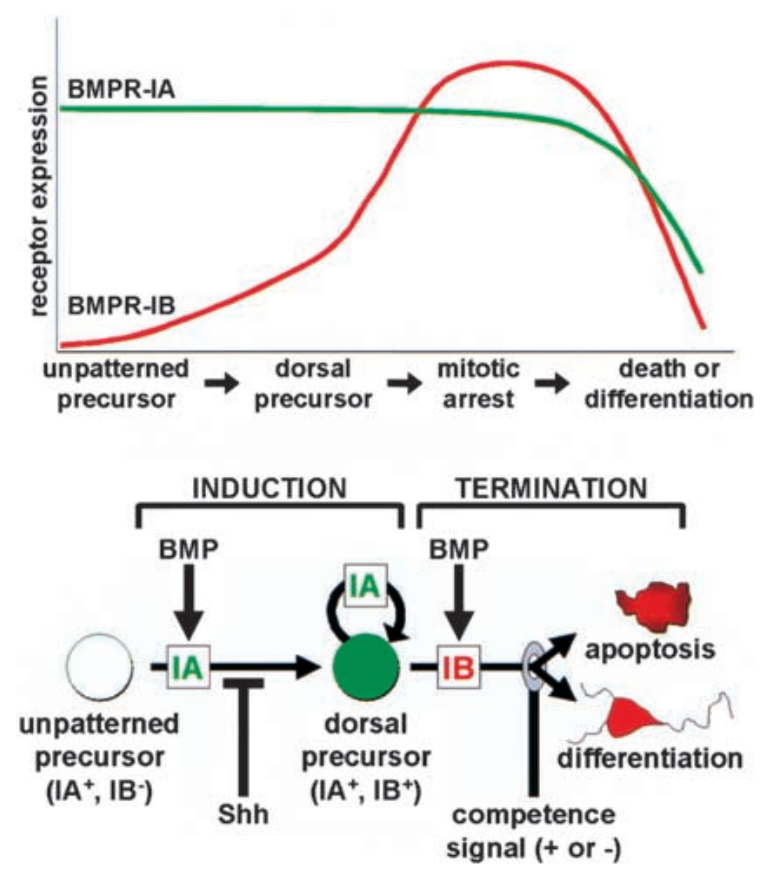

Figure 11. Induction-termination model for BMP receptor actions. In the induction phase, a precursor cell in the early postgastrulation embryo expresses only BMPR-IA and responds to BMPs by expressing dorsal identity genes (including Bmpr- $1 b$ ) and by proliferating. This response is blocked in cells of the ventral domain by the actions of Shh. The termination phase occurs when cell surface levels of accumulating BMPR-IB exceed those of BMPR-IA, so that a cell responds to BMPs with mitotic arrest. Changing competence signals $(+)$ interpret the response to BMPR-IB so that an early precursor cell terminates by apoptosis while a later precursor cell terminates by differentiation; inhibitory signals $(-)$ can delay termination response.

for $3 \times 20 \mathrm{~min}$ and incubated with secondary antibodies in $1 \times$ PBS containing $1.5 \%$ NGS for $2 \mathrm{~h}$. After washing, sections were processed using Vectastain ABC Elite peroxidase kit (Vector) and diaminobenzidine (DAB) with metal enhancer (Sigma). Sections were counterstained with eosin or cresyl violet, dehydrated, and mounted. Images were photographed in brightfield using a Zeiss Axioplan microscope and Spot digital camera (Diagnostic Instruments) and combined for figures using Photoshop 5.0 for Windows (Adobe).

\section{BrdU staining and counting}

Pregnant recipient mice were injected with $50 \mathrm{mg}$ BrdU per gram body weight $1 \mathrm{~h}$ before being killed. Embryos were collected, processed, and sectioned as described above. Staining was performed as described above using anti-BrdU (BectonDickenson 347580), with the addition of an incubation in $0.1 \%$ (w/v) trypsin (Sigma), $0.1 \%(\mathrm{w} / \mathrm{v}) \mathrm{CaCl}_{2}$ in $0.1 \mathrm{M}$ Tris $(\mathrm{pH} 7.5)$ for $10 \mathrm{~min}$, followed by $2 \mathrm{~N} \mathrm{HCl}$ in PBS for $30 \mathrm{~min}$ before blocking. $\mathrm{BrdU}^{+}$cells were counted using Stereo Investigator (Microbrightfield), and a Student $t$-test was used to determine statistical significance.

\section{In situ hybridization}

Embryos were fixed, processed, and sectioned as described above. In situ hybridization using $\mathrm{S}^{35}$-labeled riboprobes was performed as described (Hogan et al. 1994). Template cDNAs used for probe synthesis were generated by RT-PCR, and their sequence was verified, including Wnt1 (mouse, accession no. M11943, bases 1053-1732), Foxi1/Hfh4 (mouse, accession no. L13204, 1633-2112), Foxg1/Bf1 (mouse, accession no. U36760, 375-1167), Bmpr-1a (human, accession no. Z22535, 310-868), and Bmpr-1b (mouse, accession no. Z23143, 1-742). Autoradiographic emulsions were performed as described (Hogan et al. 1994) and were exposed 4-14 d.

\section{In vitro stem cell culturing and analysis}

E14.5 cortical and E12.5 ventral midbrain stem cells were isolated and cultured as described (Johe et al. 1996; Studer et al. 1998). Experiments were performed at passage 0 or 1 for ventral mesencephalic cultures, and at passages 1 through 4 for cortical cultures. All experiments were performed in the presence of 10 ng/mL bFGF (R\&D Systems) as a stem cell mitogen. BMP2 (Genetics Institute or R\&D Systems), Shh (R\&D Systems), and cyclopamine (gift of W. Gaffield, US Department of Agriculture, Albany, CA) were applied continuously for induction experiments. Shh was applied for $20 \mathrm{~min}$ before addition of BMP2. Cells were fixed in cold fresh $4 \%$ paraformaldehyde $(\mathrm{pH} 7.2)$ for 5 to $15 \mathrm{~min}$, washed in $1 \times$ PBS, blocked with $5 \%$ serum, and stained with primary antibodies $(2 \mathrm{~h})$ as described above. Cells were incubated with fluorescent secondary antibodies as directed (Jackson ImmunoResearch) for $1 \mathrm{~h}$, washed, and mounted using Vectashield with DAPI (Vector).

Transfections of cortical stem cells were performed using Lipofectamine Plus reagent as recommended (Life Technologies) and the four pNERV-driven mutant Bmpr constructs described above. Cells were plated at $7 \times 10^{4}$ cells per $6-\mathrm{cm}$ dish and expanded in N2 plus $10 \mathrm{ng} / \mathrm{mL}$ bFGF without penicillin/streptomycin for $3 \mathrm{~d}$ before transfection. Cells were transfected for $3 \mathrm{~h}$ in $2 \mathrm{~mL}$ medium containing $1.3 \mathrm{mg}$ DNA for each construct $(2.6$ mg total); pNERV.lacZ was used as needed to keep total DNA concentrations constant between groups. These conditions yielded an $8 \%$ to $10 \%$ transfection efficiency. Cells transfected with pNERV.lacZ alone showed no changes in growth or phenotype when compared with untransfected controls. Double staining with antibodies against $\mathrm{HA}$ and Flag tags confirmed that $98 \%$ of transfected cells contained both constructs (data not shown).

For gene expression analysis, cultures were harvested in Trizol (Life Technologies) for isolation of RNA, which was then used for first-strand cDNA synthesis (Superscript II, Life Technologies). RT-PCR was performed using the following primers and conditions: Bmpr-1a (rat, accession no. S75359, nucleotides 1564-1585 and 2027-2006, 471-bp product), $2.0 \mathrm{mM} \mathrm{MgCl}_{2}$, $55.1^{\circ} \mathrm{C}$ annealing, 29 cycles; Bmpr-1b (mouse, accession no. Z23143, nucleotides 85-106 and 403-379, 319-bp product), 2.0 $\mathrm{mM} \mathrm{MgCl} 2,56.0^{\circ} \mathrm{C}$ annealing, 29 cycles; Msx1 (rat, accession no. D83036, nucleotides 690-711 and 1026-1003, 337-bp product), $1.5 \mathrm{mM} \mathrm{MgCl}_{2}, 60.3^{\circ} \mathrm{C}$ annealing, 32 cycles; and GAPDH (rat, accession no. M17701, nucleotides 14-39 and 318-295, 305-bp product), $2.0 \mathrm{mM} \mathrm{MgCl}_{2}, 55.0^{\circ} \mathrm{C}$ annealing, 21 cycles.

\section{Acknowledgments}

We would like to thank Dr. Lee Niswander for her generous gift of the mutant Bmpr-1a and Bmpr-1b constructs. BMP2 was supplied by agreement with Genetics Institute. Activated Caspase3 antibody (CM1) was supplied by agreement with Idun Pharmaceuticals. Monoclonal antibodies for Pax7 (from Dr. A. Kawakami) and Islet1 (40.2D6 from Dr. T. Jessell) were obtained 
from the Developmental Studies Hybridoma Bank. We are grateful for the gift of Pax6 antibody from Dr. Randall Reed and cyclopamine from Dr. William Gaffield). We also thank Dr. James Nagle of the NINDS DNA-sequencing facility for sequence verification of constructs; Drs. Heather Cameron and Susan Wray for technical advice; and Dr. Martin Sailer, Helen Mitchell, Michael Nguyen, Emily Liu, and Martha Kimos for excellent technical assistance.

The publication costs of this article were defrayed in part by payment of page charges. This article must therefore be hereby marked "advertisement" in accordance with 18 USC section 1734 solely to indicate this fact.

\section{References}

Altmann, C.R. and Brivanlou, A.H. 2001. Neural patterning in the vertebrate embryo. Int. Rev. Cytol. 203: 447-482.

Amthor, H., Christ, B., Weil, M., and Patel, K. 1998. The importance of timing differentiation during limb muscle development. Curr. Biol. 8: 642-652.

Amthor, H., Christ, B., and Patel, K. 1999. A molecular mechanism enabling continuous embryonic muscle growth: A balance between proliferation and differentiation. Development 126: 1041-1053.

Arkell, R. and Beddington, R.S. 1997. BMP-7 influences pattern and growth of the developing hindbrain of mouse embryos. Development 124: 1-12.

Bachiller, D., Klingensmith, J., Kemp, C., Belo, J.A., Anderson, R.M., May, S.R., McMahon, J.A., McMahon, A.P., Harland, R.M., Rossant, J., et al. 2000. The organizer factors Chordin and Noggin are required for mouse forebrain development. Nature 403: 658-661.

Bang, A.G., Papalopulu, N., Goulding, M.D., and Kintner, C. 1999. Expression of Pax-3 in the lateral neural plate is dependent on a Wnt-mediated signal from posterior nonaxial mesoderm. Dev. Biol. 212: 366-380.

Barth, K.A., Kishimoto, Y., Rohr, K.B., Seydler, C., SchulteMerker, S., and Wilson, S.W. 1999. Bmp activity establishes a gradient of positional information throughout the entire neural plate. Development 126: 4977-4987.

Baur, S.T., Mai, J.J., and Dymecki, S.M. 2000. Combinatorial signaling through BMP receptor IB and GDF5: Shaping of the distal mouse limb and the genetics of distal limb diversity. Development 127: 605-619.

Bendall, A.J. and Abate-Shen, C. 2000. Roles for Msx and Dlx homeoproteins in vertebrate development. Gene 247: 17-31.

Briscoe, J. and Ericson, J. 1999. The specification of neuronal identity by graded Sonic Hedgehog signalling. Semin. Cell Dev. Biol. 10: 353-362.

Burke, R. and Basler, K. 1996. Dpp receptors are autonomously required for cell proliferation in the entire developing Drosophila wing. Development 122: 2261-2269.

Charron, G., Julien, J.P., and Bibor-Hardy, V. 1995. Neuron specificity of the neurofilament light promoter in transgenic mice requires the presence of DNA unwinding elements. J. Biol. Chem. 270: 25739-25745.

Chen, R.H., Su, Y.H., Chuang, R.L., and Chang, T.Y. 1998. Suppression of transforming growth factor- $\beta$-induced apoptosis through a phosphatidylinositol 3-kinase/Akt-dependent pathway. Oncogene 17: 1959-1968.

Coffman, F.D. and Studzinski, G.P. 1999. Differentiation-related mechanisms which suppress DNA replication. Exp. Cell Res. 248: 58-73.

Cooper, M.K., Porter, J.A., Young, K.E., and Beachy, P.A. 1998. Teratogen-mediated inhibition of target tissue response to
Shh signaling. Science 280: 1603-1607.

Cornell, R.A. and Ohlen, T.V. 2000. Vnd/nkx, ind/gsh, and msh/ msx: Conserved regulators of dorsoventral neural patterning? Curr. Opin. Neurobiol. 10: 63-71.

Dale, L. 2000. Pattern formation: A new twist to BMP signalling. Curr. Biol. 10: R671-R673

Day, S.J. and Lawrence, P.A. 2000. Measuring dimensions: The regulation of size and shape. Development 127: 2977-2987.

Dewulf, N., Verschueren, K., Lonnoy, O., Moren, A., Grimsby, S., Vande, S.K., Miyazono, K., Huylebroeck, D., and ten Dijke, P. 1995. Distinct spatial and temporal expression patterns of two type I receptors for bone morphogenetic proteins during mouse embryogenesis. Endocrinology 136: 26522663.

Dudley, A.T. and Robertson, E.J. 1997. Overlapping expression domains of bone morphogenetic protein family members potentially account for limited tissue defects in BMP7 deficient embryos. Dev. Dyn. 208: 349-362.

Edgar, B.A. and Lehner, C.F. 1996. Developmental control of cell cycle regulators: A fly's perspective. Science 274: 16461652.

Entchev, E.V., Schwabedissen, A., and Gonzalez-Gaitan, M. 2000. Gradient formation of the TGF- $\beta$ homolog Dpp. Cell 103: 981-991.

Furuta, Y., Piston, D.W., and Hogan, B.L. 1997. Bone morphogenetic proteins (BMPs) as regulators of dorsal forebrain development. Development 124: 2203-2212.

Garcia-Castro, M. and Bronner-Fraser, M. 1999. Induction and differentiation of the neural crest. Curr. Opin. Cell Biol. 11: 695-698.

Golden, J.A. 1999. Towards a greater understanding of the pathogenesis of holoprosencephaly. Brain Dev. 21: 513-521.

Golden, J.A., Bracilovic, A., McFadden, K.A., Beesley, J.S., R. Rubenstein, J.L., and Grinspan, J.B. 1999. Ectopic bone morphogenetic proteins 5 and 4 in the chicken forebrain lead to cyclopia and holoprosencephaly. Proc. Natl. Acad. Sci. 96: $2439-2444$.

Graham, A., Koentges, G., and Lumsden, A. 1996. Neural crest apoptosis and the establishment of craniofacial pattern: An honorable death. Mol. Cell Neurosci. 8: 76-83.

Gross, R.E., Mehler, M.F., Mabie, P.C., Zang, Z., Santschi, L., and Kessler, J.A. 1996. Bone morphogenetic proteins promote astroglial lineage commitment by mammalian subventricular zone progenitor cells. Neuron 17: 595-606.

Grove, E.A., Tole, S., Limon, J., Yip, L., and Ragsdale, C.W. 1998. The hem of the embryonic cerebral cortex is defined by the expression of multiple Wnt genes and is compromised in Gli3-deficient mice. Development 125: 2315-2325.

Haydar, T.F., Bambrick, L.L., Krueger, B.K., and Rakic, P. 1999. Organotypic slice cultures for analysis of proliferation, cell death, and migration in the embryonic neocortex. Brain Res. Brain Res. Protoc. 4: 425-437.

Hogan B.L.M., Beddington, R.S.P., Costantini, F., and Lacy, E. 1994. Manipulating the mouse embryo: A laboratory manual. Cold Spring Harbor Laboratory Press, Plainview, NY.

Hu, P.P., Shen, X., Huang, D., Liu, Y., Counter, C., and Wang, X.F. 1999. The MEK pathway is required for stimulation of p21(WAF1/CIP1) by transforming growth factor- $\beta$. J. Biol. Chem. 274: 35381-35387.

Ishidou, Y., Kitajima, I., Obama, H., Maruyama, I., Murata, F., Imamura, T., Yamada, N., ten Dijke, P., Miyazono, K., and Sakou, T. 1995. Enhanced expression of type I receptors for bone morphogenetic proteins during bone formation. J. Bone Miner. Res. 10: 1651-1659.

Itoh, S., Itoh, F., Goumans, M.J., and ten Dijke, P. 2000. Signal- 
ing of transforming growth factor- $\beta$ family members through smad proteins. Eur. J. Biochem. 267: 6954-6967.

Iwasaki, S., Iguchi, M., Watanabe, K., Hoshino, R., Tsujimoto, M., and Kohno, M. 1999. Specific activation of the p38 mitogen-activated protein kinase signaling pathway and induction of neurite outgrowth in PC12 cells by bone morphogenetic protein-2. J. Biol. Chem. 274: 26503-26510.

Jernvall, J., Aberg, T., Kettunen, P., Keranen, S., and Thesleff, I. 1998. The life history of an embryonic signaling center: BMP-4 induces p21 and is associated with apoptosis in the mouse tooth enamel knot. Development 125: 161-169.

Johe, K.K., Hazel, T.G., Muller, T., Dugich-Djordjevic, M.M., and McKay, R.D. 1996. Single factors direct the differentiation of stem cells from the fetal and adult central nervous system. Genes \& Dev. 10: 3129-3140.

Josephson, R., Muller, T., Pickel, J., Okabe, S., Reynolds, K., Turner, P.A., Zimmer, A., and McKay, R.D. 1998. POU transcription factors control expression of CNS stem cell-specific genes. Development 125: 3087-3100.

Jurata, L.W., Thomas, J.B., and Pfaff, S.L. 2000. Transcriptional mechanisms in the development of motor control. Curr. Opin. Neurobiol. 10: 72-79.

Kaestner, K.H., Knochel, W., and Martinez, D.E. 2000. Unified nomenclature for the winged helix/forkhead transcription factors. Genes \& Dev. 14: 142-146.

Kalyani, A.J., Piper, D., Mujtaba, T., Lucero, M.T., and Rao, M.S. 1998. Spinal cord neuronal precursors generate multiple neuronal phenotypes in culture. J. Neurosci. 18: 7856-7868.

Kawabata, M., Imamura, T., and Miyazono, K. 1998. Signal transduction by bone morphogenetic proteins. Cytokine Growth Factor Rev. 9: 49-61.

Kim, I.Y., Lee, D.H., Ahn, H.J., Tokunaga, H., Song, W., Devereaux, L.M., Jin, D., Sampath, T.K., and Morton, R.A. 2000. Expression of bone morphogenetic protein receptors type-IA, -IB and -II correlates with tumor grade in human prostate cancer tissues. Cancer Res. 60: 2840-2844.

Kimura, N., Matsuo, R., Shibuya, H., Nakashima, K., and Taga, T. 2000. BMP2-induced apoptosis is mediated by activation of the TAK1-p38 kinase pathway that is negatively regulated by Smad6. J. Biol. Chem. 275: 17647-17652.

Kretzschmar, M., Doody, J., and Massague, J. 1997. Opposing BMP and EGF signalling pathways converge on the TGF- $\beta$ family mediator Smad1. Nature 389: 618-622.

Krishna, S., Maduzia, L.L., and Padgett, R.W. 1999. Specificity of TGF $\beta$ signaling is conferred by distinct type I receptors and their associated SMAD proteins in Caenorhabditis elegans. Development 126: 251-260.

Lecuit, T. and Cohen, S.M. 1998. Dpp receptor levels contribute to shaping the Dpp morphogen gradient in the Drosophila wing imaginal disc. Development 125: 4901-4907.

Lee, K.J., Mendelsohn, M., and Jessell, T.M. 1998. Neuronal patterning by BMPs: A requirement for GDF7 in the generation of a discrete class of commissural interneurons in the mouse spinal cord. Genes \& Dev. 12: 3394-3407.

Li, W., Cogswell, C.A., and LoTurco, J.J. 1998. Neuronal differentiation of precursors in the neocortical ventricular zone is triggered by BMP. J. Neurosci. 18: 8853-8862.

Liem, K.F.J., Tremml, G., Roelink, H., and Jessell, T.M. 1995. Dorsal differentiation of neural plate cells induced by BMPmediated signals from epidermal ectoderm. Cell 82: 969979.

Liem, K.F.J., Tremml, G., and Jessell, T.M. 1997. A role for the roof plate and its resident TGF $\beta$-related proteins in neuronal patterning in the dorsal spinal cord. Cell 91: 127-138.

Lim, L., Zhou, H., and Costa, R.H. 1997. The winged helix transcription factor HFH-4 is expressed during choroid plexus epithelial development in the mouse embryo. Proc. Nat1. Acad. Sci. 94: 3094-3099.

Mabie, P.C., Mehler, M.F., and Kessler, J.A. 1999. Multiple roles of bone morphogenetic protein signaling in the regulation of cortical cell number and phenotype. J. Neurosci. 19: 70777088.

McMahon, J.A., Takada, S., Zimmerman, L.B., Fan, C.M., Harland, R.M., and McMahon, A.P. 1998. Noggin-mediated antagonism of BMP signaling is required for growth and patterning of the neural tube and somite. Genes \& Dev. 12: $1438-1452$.

Mehler, M.F., Mabie, P.C., Zhu, G., Gokhan, S., and Kessler, J.A. 2000. Developmental changes in progenitor cell responsiveness to bone morphogenetic proteins differentially modulate progressive CNS lineage fate. Dev. Neurosci. 22: 74-85.

Merino, R., Ganan, Y., Macias, D., Economides, A.N., Sampath, K.T., and Hurle, J.M. 1998. Morphogenesis of digits in the avian limb is controlled by FGFs, TGF $\beta$, and noggin through BMP signaling. Dev. Biol. 200: 35-45.

Merino, R., Macias, D., Ganan, Y., Rodriguez-Leon, J., Economides, A.N., Rodriguez-Esteban, C., Izpisua-Belmonte, J.C., and Hurle, J.M. 1999. Control of digit formation by activin signalling. Development 126: 2161-2170.

Mishina, Y., Suzuki, A., Ueno, N., and Behringer, R.R. 1995. Bmpr encodes a type I bone morphogenetic protein receptor that is essential for gastrulation during mouse embryogenesis. Genes \& Dev. 9: 3027-3037.

Molne, M., Studer, L., Tabar, V., Ting, Y.T., Eiden, M.V., and McKay, R.D. 2000. Early cortical precursors do not undergo LIF-mediated astrocytic differentiation. I. Neurosci. Res. 59: 301-311.

Monzen, K., Shiojima, I., Hiroi, Y., Kudoh, S., Oka, T., Takimoto, E., Hayashi, D., Hosoda, T., Habara-Ohkubo, A., Nakaoka, T., et al. 1999. Bone morphogenetic proteins induce cardiomyocyte differentiation through the mitogen-activated protein kinase kinase kinase TAK1 and cardiac transcription factors Csx/Nkx-2.5 and GATA-4. Mol. Cell. Biol. 19: 7096-7105.

Morrison, S.J., White, P.M., Zock, C., and Anderson, D.J. 1999. Prospective identification, isolation by flow cytometry, and in vivo self-renewal of multipotent mammalian neural crest stem cells. Cell 96: 737-749.

Morrison, S.J., Perez, S.E., Qiao, Z., Verdi, J.M., Hicks, C., Weinmaster, G., and Anderson, D.J. 2000. Transient Notch activation initiates an irreversible switch from neurogenesis to gliogenesis by neural crest stem cells. Cell 101: 499-510.

Mujtaba, T., Mayer-Proschel, M., and Rao, M.S. 1998. A common neural progenitor for the CNS and PNS. Dev. Biol. 200: $1-15$.

Nakamura, K., Shirai, T., Morishita, S., Uchida, S., Saeki-Miura, K., and Makishima, F. 1999. p38 mitogen-activated protein kinase functionally contributes to chondrogenesis induced by growth/differentiation factor-5 in ATDC5 cells. Exp. Cell Res. 250: 351-363.

Nakayama, T., Cui, Y., and Christian, J.L. 2000. Regulation of BMP/Dpp signaling during embryonic development. Cell Mol. Life Sci. 57: 943-956.

Nguyen, V.H., Schmid, B., Trout, J., Connors, S.A., Ekker, M., and Mullins, M.C. 1998. Ventral and lateral regions of the zebrafish gastrula, including the neural crest progenitors, are established by a bmp2b/swirl pathway of genes. Dev. Biol. 199: 93-110.

Nguyen, V.H., Trout, J., Connors, S.A., Andermann, P., Weinberg, E., and Mullins, M.C. 2000. Dorsal and intermediate neuronal cell types of the spinal cord are established by a BMP signaling pathway. Development 127: 1209-1220. 
Nikaido, M., Tada, M., Takeda, H., Kuroiwa, A., and Ueno, N. 1999. In vivo analysis using variants of zebrafish BMPR-IA: Range of action and involvement of BMP in ectoderm patterning. Development 126: 181-190.

Pizette, S. and Niswander, L. 2000. BMPs are required at two steps of limb chondrogenesis: Formation of prechondrogenic condensations and their differentiation into chondrocytes. Dev. Biol. 219: 237-249.

Sakou, T. 1998. Bone morphogenetic proteins: From basic studies to clinical approaches. Bone 22: 591-603.

Shah, N.M., Groves, A.K., and Anderson, D.J. 1996. Alternative neural crest cell fates are instructively promoted by TGF $\beta$ superfamily members. Cell 85: 331-343.

Solloway, M.J., Dudley, A.T., Bikoff, E.K., Lyons, K.M., Hogan, B.L., and Robertson, E.J. 1998. Mice lacking Bmp6 function. Dev. Genet. 22: 321-339.

Srinivasan, A., Roth, K.A., Sayers, R.O., Shindler, K.S., Wong, A.M., Fritz, L.C., and Tomaselli, K.J. 1998. In situ immunodetection of activated caspase-3 in apoptotic neurons in the developing nervous system. Cell Death. Differ. 5: 10041016.

Studer, L., Tabar, V., and McKay, R.D. 1998. Transplantation of expanded mesencephalic precursors leads to recovery in parkinsonian rats. Nat. Neurosci. 1: 290-295.

Sun, Y., Nadal-Vicens, M., Misono, S., Lin, M.Z., Zubiaga, A., Hua, X., Fan, G., and Greenberg, M.E. 2001. Neurogenin promotes neurogenesis and inhibits glial differentiation by independent mechanisms. Cell 104: 365-376.

Suzuki, Y., Yandell, M.D., Roy, P.J., Krishna, S., Savage-Dunn, C., Ross, R.M., Padgett, R.W., and Wood, W.B. 1999. A BMP homolog acts as a dose-dependent regulator of body size and male tail patterning in Caenorhabditis elegans. Development 126: 241-250.

Tao, W. and Lai, E. 1992. Telencephalon-restricted expression of BF-1, a new member of the HNF-3/fork head gene family, in the developing rat brain. Neuron 8: 957-966.

Teleman, A.A. and Cohen, S.M. 2000. Dpp gradient formation in the Drosophila wing imaginal disc. Cell 103: 971-980.

Tsai, R.Y. and McKay, R.D. 2000. Cell contact regulates fate choice by cortical stem cells. I. Neurosci. 20: 3725-3735.

Vogt, T.F. and Duboule, D. 1999. Antagonists go out on a limb. Cell 99: 563-566.

Yamada, N., Kato, M., ten Dijke, P., Yamashita, H., Sampath, T.K., Heldin, C.H., Miyazono, K., and Funa, K. 1996. Bone morphogenetic protein type IB receptor is progressively expressed in malignant glioma tumours. Br. J. Cancer 73: 624629.

Yamaguchi, K., Nagai, S., Ninomiya-Tsuji, J., Nishita, M., Tamai, K., Irie, K., Ueno, N., Nishida, E., Shibuya, H., and Matsumoto, K. 1999. XIAP, a cellular member of the inhibitor of apoptosis protein family, links the receptors to TAB1TAK1 in the BMP signaling pathway. EMBO J. 18: 179-187.

Yi, S.E., Daluiski, A., Pederson, R., Rosen, V., and Lyons, K.M. 2000. The type I BMP receptor BMPRIB is required for chondrogenesis in the mouse limb. Development 127: 621-630.

Yoshikawa, K. 2000. Cell cycle regulators in neural stem cells and postmitotic neurons. Neurosci. Res. 37: 1-14.

Zhang, D., Mehler, M.F., Song, Q., and Kessler, J.A. 1998. Development of bone morphogenetic protein receptors in the nervous system and possible roles in regulating trkC expression. J. Neurosci. 18: 3314-3326.

Zhao, R., Lawler, A.M., and Lee, S.J. 1999. Characterization of GDF-10 expression patterns and null mice. Dev. Biol. 212: 68-79.

Zhu, G., Mehler, M.F., Mabie, P.C., and Kessler, J.A. 1999. Developmental changes in progenitor cell responsiveness to cy- tokines. J. Neurosci. Res. 56: 131-145.

Zou, H., Wieser, R., Massague, J., and Niswander, L. 1997. Distinct roles of type I bone morphogenetic protein receptors in the formation and differentiation of cartilage. Genes \& Dev. 11: 2191-2203. 


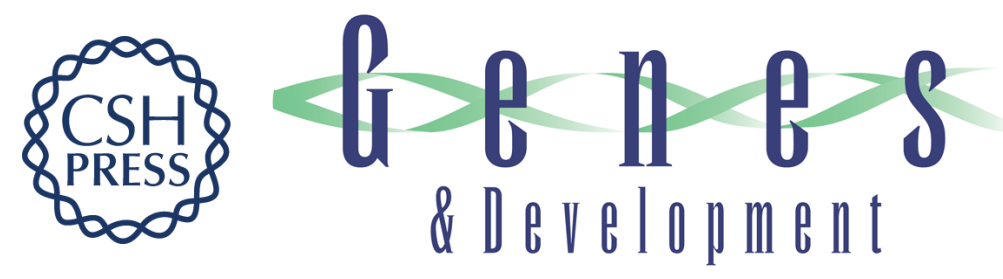

\section{Sequential actions of BMP receptors control neural precursor cell production and fate}

David M. Panchision, James M. Pickel, Lorenz Studer, et al.

Genes Dev. 2001, 15:

Access the most recent version at doi:10.1101/gad.894701

References This article cites 87 articles, 39 of which can be accessed free at: http://genesdev.cshlp.org/content/15/16/2094.full.html\#ref-list-1

License

Email Alerting

Receive free email alerts when new articles cite this article - sign up in the box at the top Service right corner of the article or click here.

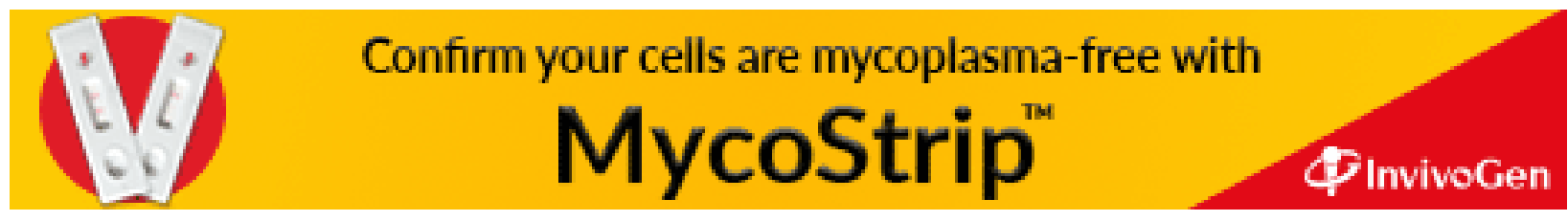

